OPEN ACCESS

Edited by:

Flavia Trettel,

Sapienza University of Rome, Italy

Reviewed by:

Silvia Zucchelli,

University of Eastern Piedmont, Italy Marta Biagioli, University of Trento, Italy

${ }^{*}$ Correspondence: Naoko Tanese tanesn01@med.nyu.edu

Received: 11 September 2016 Accepted: 06 February 2017

Published: 21 February 2017

Citation:

Yu MS and Tanese N (2017) Huntingtin Is Required for Neural But Not Cardiac/Pancreatic Progenitor Differentiation of Mouse Embryonic Stem Cells In vitro.

Front. Cell. Neurosci. 11:33. doi: 10.3389/fncel.2017.00033

\section{Huntingtin Is Required for Neural But Not Cardiac/Pancreatic Progenitor Differentiation of Mouse Embryonic Stem Cells In vitro}

\author{
Man Shan Yu and Naoko Tanese* \\ Department of Microbiology, New York University School of Medicine, New York, NY, USA
}

Mutation in the huntingtin (HTT) gene causes Huntington's disease (HD). It is an autosomal dominant trinucleotide-repeat expansion disease in which CAG repeat sequence expands to $>35$. This results in the production of mutant $\mathrm{HTT}$ protein with an increased stretch of glutamines near the $\mathrm{N}$-terminus. The wild type HTT gene encodes a $350 \mathrm{kD}$ protein whose function remains elusive. Mutant $\mathrm{HTT}$ protein has been implicated in transcription, axonal transport, cytoskeletal structure/function, signal transduction, and autophagy. HD is characterized by the appearance of nuclear inclusions and degeneration of the striatum. Although HTT protein is expressed early in embryos, most patients develop symptoms in mid-life. It is also unclear why the ubiquitously expressed mutant HTT specifically causes striatal atrophy. Wild type Htt is essential for development as $\mathrm{Htt}$ knockout mice die at day E7.5. Increasing evidence suggests mutant Htt may alter neurogenesis and development of striatal neurons resulting in neuronal loss. Using a mouse embryonic stem cell model, we examined the role of Htt in neural differentiation. We found cells lacking Htt inefficient in generating neural stem cells. In contrast differentiation into progenitors of mesoderm and endoderm lineages was not affected. The data suggests $\mathrm{Htt}$ is essential for neural but not cardiac/pancreatic progenitor differentiation of embryonic stem cells in vitro.

Keywords: Huntington's disease, huntingtin gene, embryonic stem cells, neural differentiation, embryoid bodies, neural stem cells

\section{INTRODUCTION}

Human HTT is a large protein of approximately $350 \mathrm{kDa}$ made up of 3144 amino acids. It is nearly ubiquitously expressed with the highest level of expression in the brain and the testes. The size and predicted structure of the protein suggest its role as a protein scaffold that coordinates a multitude of cellular functions (reviewed in Saudou and Humbert, 2016). Studies have reported pro-survival properties of wild type Htt. It protects cells from cell death induced by a variety of stimuli including serum withdrawal (Rigamonti et al., 2000), mutant Htt (Leavitt et al., 2001), and NMDA receptormediated excitotoxicity (Leavitt et al., 2006). Htt has effects on gene transcription by binding

\footnotetext{
Abbreviations: EBs, embryoid bodies; GFAP, glial fibrillary acidic protein; HD, Huntington's disease; Htt, huntingtin; ITSFn, insulin/transferrin/selenium/fibronectin; Kdm6a, lysine-specific demethylase 6A; MaoA, monoamine oxidase A; mESCs, mouse embryonic stem cells; NSCs, neural stem cells; PRC, polycomb repressive complex.
} 
to transcriptional regulators such as the repressor RE1-silencing transcription factor (Zuccato et al., 2003), p53 and CREBbinding protein (Steffan et al., 2000), NeuroD (Marcora et al., 2003), NF-кB (Takano and Gusella, 2002) and transcriptional activator Sp1 and co-activator TAF 130 (Dunah et al., 2002). $\mathrm{Htt}$ is involved in transport of a variety of vesicles including brain-derived neurotrophic factor-containing vesicles (Gauthier et al., 2004), synaptic precursor vesicles (Zala et al., 2013), and GABA receptor-containing vesicles (Twelvetrees et al., 2010). Htt coordinates cell division through the regulation of spindle pole assembly during mitosis (Godin et al., 2010; Elias et al., 2014). Moreover, Htt is reported involved in ciliogenesis (Keryer et al., 2011), endosomal trafficking (Pal et al., 2006), and autophagy (Kegel et al., 2000; Ravikumar et al., 2004).

Wild type $\mathrm{Htt}$ is essential for embryonic development as knockout of $\mathrm{Htt}$ in mice results in embryonic death at day 7.5 (Duyao et al., 1995; Nasir et al., 1995; Zeitlin et al., 1995). Htt may be needed for neurogenesis as reduced expression of wild type Htt causes impaired brain development and abnormal vascular morphogenesis in mice (White et al., 1997). Others reported cells without Htt can be differentiated into functional neurons (Metzler et al., 1999) or glial cells (Conforti et al., 2013). Thus, Htt's role in neural development remains unclear.

Abnormal neurogenesis has been observed in HD. Increased cell proliferation and neurogenesis were found in human postmortem HD brains (Curtis et al., 2003), and in the quinolinic acid lesion rat model of HD (Tattersfield et al., 2004). Similarly, mutant Htt caused faster neuronal differentiation of embryonic and NSCs in vitro (Lorincz and Zawistowski, 2009). In contrast, reduced hippocampal neurogenesis was observed in R6/2 transgenic HD mice (Gil et al., 2005). Increasing evidence suggests mutant $\mathrm{Htt}$ causes dysregulated neurogenesis. In the HD R6/2 mice, expansion of striatal NSCs and altered migration of neural progenitor cells into the striatum were observed (Batista et al., 2006). A study reported that Q111 Htt knock-in mice (with glutamine repeats expanded to 111) exhibited defects in specification and maturation of striatal medium spiny neurons (Molero et al., 2009). Mutant Htt was also shown to affect cortical development by causing spindle misorientation in dividing cortical progenitors (Molina-Calavita et al., 2014). Selective expression of mutant Htt in mice up to postnatal day 21 resulted in impairment similar to mice expressing mutant Htt throughout life (Molero et al., 2016). Furthermore, mice expressing very low levels of Htt up to postnatal day 21 also exhibited latelife neurodegeneration phenotypes (Arteaga-Bracho et al., 2016). These studies suggest developmental abnormalities resulting from early mutant Htt expression or very low Htt expression may contribute to the pathogenesis of HD.

Neural stem cells derived from HD mice, or ES cells expressing mutant Htt or no Htt (Htt-null) have been studied for growth, motility, and biochemical properties (Ritch et al., 2012). Interestingly, NS cells derived from HD mouse brains showed reduced levels of cholesterol, increased reactive oxygen species, and impaired motility compared with NS cells from wild type animals, recapitulating phenotypes seen in HD patients. In contrast, Htt knockout (KO) NS cells derived from $\mathrm{Htt}$-KO ES cells had increased cholesterol levels. Nguyen et al. used a neural induction culture model to examine stages of neural induction in ESCs expressing mutant Htt or in $\mathrm{Htt}$-KO ESCs (Nguyen et al., 2013a). They reported disruption of proliferation, self-renewal, and the specification of NSCs in Htt-KO cells while mutant Htt enhanced neurogenesis. Htt-KO NSCs also showed increased endodermal and mesodermal gene expression suggesting Htt may be involved in neural and non-neural fate decisions. The same group also examined lineage differentiation of $\mathrm{Htt}$-KO ESCs and ESCs expressing mutant Htt (Nguyen et al., 2013b). They found Htt required in the differentiation of ESCs into ectoderm, endoderm, and mesoderm while mutant Htt differentially impaired stage-specific developmental events.

Recent investigations on how mutant Htt affects neural development as well as the role of wild type Htt in neural development suggest neurodegeneration may result from both gain of toxic mutant $\mathrm{Htt}$ function and loss of wild type $\mathrm{Htt}$ function. In this study, we used the 5-stage differentiation protocol (Schroeder et al., 2009) to differentiate mouse ESCs lacking $\mathrm{Htt}$ to different cell lineages and examined the role of $\mathrm{Htt}$ in progenitor cell differentiation. We found $\mathrm{Htt}$ is required for ectoderm, but not mesoderm or endoderm differentiation under our experimental conditions.

\section{MATERIALS AND METHODS}

\section{Mouse Embryonic Stem Cell Culture}

Four mESC lines used in this study are generous gifts of Dr. Scott O. Zeitlin (University of Virginia). They are: (1) R1, parental wild type ES cells; (2) $H t t$-null (HN), Htt nullizygous ES cells in which the promoter and exon 1 sequence of Htt were deleted (Zeitlin et al., 1995); (3) 7Q, 3xFlag-Htt ${ }^{7 Q / 7 Q}$ ES cells that express wild type Htt Flag-tagged at the N-terminus; (4) 140Q, heterozygous 3xFlag-Htt ${ }^{140 Q / 7 Q}$ ES cells carrying an $\mathrm{Htt}$ allele with an expanded polyQ tagged with a $3 x F L A G$ tag at the N-terminus (Zheng et al., 2012).

Mouse embryonic stem cells were maintained undifferentiated on $0.1 \%$ gelatin-coated plates under feeder-free culture conditions in standard ES medium containing Dulbecco's minimal essential medium (DMEM, Cellgro) supplemented with 15\% ES-Cult FBS (STEMCELL Technologies), 1X Penicillin-Streptomycin-Glutamine (P/S/Q), $1 \mathrm{mM}$ sodium pyruvate, $1 \mathrm{X}$ non-essential amino acids (NEAA), and $0.1 \mathrm{mM}$ $\beta$-mercaptoethanol (all from GIBCO), $10^{3}$ Units/ml ESGRO mouse Leukemia Inhibitory Factor (LIF, Millipore), and $2 \mu \mathrm{M} \mathrm{SU}$ 5402 (VEGFR and FGFR inhibitor; Tocris Bioscience), $0.8 \mu \mathrm{M}$ PD184352, and $3 \mu \mathrm{M}$ CHIR99021 (MEK and GSK3 inhibitors, respectively, both from BioVision). Standard ES medium was changed daily and cells were passaged every 2-3 days using $0.05 \%$ Trypsin/EDTA.

\section{5-Stage Neural Cell Differentiation}

Mouse embryonic stem cells were differentiated into neural cells according to the 5-stage neural differentiation protocol developed by Dr. Ronald D.G. McKay (Okabe et al., 1996; Lee et al., 2000). Undifferentiated ES cells (Stage 1) were grown as described above for at least three passages before proceeding to the next stage. 
To induce EBs formation (Stage 2), mESCs were dissociated into single-cell suspension with $0.05 \%$ trypsin/EDTA and plated onto $100 \mathrm{~mm}$ non-adherent bacterial petri dishes $\left(2 \times 10^{6}\right.$ cells per dish) in the standard ES medium without LIF and the inhibitors. Floating EBs formed spontaneously were cultured for 4 days in suspension, collected and plated onto $100 \mathrm{~mm}$ tissue culture plates in the standard ES medium without LIF and the inhibitors.

After EBs attached to the culture plate began to differentiate (after $24 \mathrm{~h}$ ), selection of nestin-positive cells (Stage 3) was initiated by replacing the standard ES medium with the serumfree ITSFn medium, which contained DMEM/Ham's F-12 50/50 (Cellgro) supplemented with $1 \mathrm{X} \mathrm{P} / \mathrm{S} / \mathrm{Q}, 5 \mu \mathrm{g} / \mathrm{ml}$ insulin, $50 \mu \mathrm{g} / \mathrm{ml}$ human apo-transferrin, $30 \mathrm{nM}$ selenium chloride, and $5 \mu \mathrm{g} / \mathrm{ml}$ fibronectin. ITSFn medium was replenished every 2 days.

After 8 days of selection, expansion of nestin-positive cells (Stage 4) was initiated. Briefly, cells were dissociated with $0.05 \%$ trypsin/EDTA and plated on poly-L-ornithine and laminin-coated tissue culture plates or glass coverslips at a density of $1.5-2 \times 10^{5}$ cells per $\mathrm{cm}^{2}$ in the $\mathrm{N} 2$ medium containing DMEM/Ham's F-12 50/50 supplemented with $1 \mathrm{X}$ $\mathrm{P} / \mathrm{S} / \mathrm{Q}, 25 \mu \mathrm{g} / \mathrm{ml}$ insulin, $50 \mu \mathrm{g} / \mathrm{ml}$ human apo-transferrin, $30 \mathrm{nM}$ selenium chloride, $20 \mathrm{nM}$ progesterone, $100 \mu \mathrm{M}$ putrescine, $10 \mathrm{ng} / \mathrm{ml}$ bFGF (R\&D Systems), and $1 \mu \mathrm{g} / \mathrm{ml}$ laminin. Nestinpositive cells were expanded for 6 days. The medium was changed every 2 days.

Differentiation (Stage 5) was induced by withdrawing bFGF from the N2 medium. Cells were incubated under differentiation conditions for 6-15 days, changing the medium every 2 days.

\section{Alkaline Phosphatase Staining}

Alkaline phosphatase staining was used to confirm undifferentiated mESCs. Cells cultured on 6-well plates were fixed in a fixative solution (citrate buffered acetone, 60\%) for $30 \mathrm{~s}$, and rinsed gently in deionized water. Cells were incubated in an alkaline-dye mixture, which contained Fast Blue RR Salt and Naphthol AS-MX Phosphate Alkaline Solution (Sigma-Aldrich) for $30 \mathrm{~min}$ at $37^{\circ} \mathrm{C}$. Afterward, cells were rinsed thoroughly in deionized water, followed by examination under a microscope.

\section{Immunocytochemistry}

Cells cultured on glass coverslips were fixed in $4 \%$ paraformaldehyde in PBS for $10 \mathrm{~min}$, followed by permeabilization in PBS containing $0.25 \%$ Triton X-100 for 10 min. Blocking was carried out by incubation in $1 \%$ BSA in PBST (PBS $+0.1 \%$ Tween 20) for $30 \mathrm{~min}$. Cells were incubated with primary antibodies for $2 \mathrm{~h}$ at room temperature. Following antibodies were used at indicated dilutions: mouse $\alpha$-nestin (Millipore; $1: 300)$, mouse $\alpha$ - $\beta$-III tubulin (Millipore; $1: 400)$ and rabbit $\alpha$-GFAP (Sigma-Aldrich; 1:400). Fluorescently labeled goat $\alpha$-mouse/rabbit secondary antibody (1:500 for $1 \mathrm{~h}$ at room temperature) was applied to samples in the dark. Nuclear counterstaining was performed by incubating samples in $1 \mathrm{mM}$ TO-PRO-3 (Invitrogen) in PBS for 20 min followed by confocal imaging.

\section{Three Germ Layer Differentiation via Hanging-Drop EB Formation}

Htt mESC lines were induced to differentiate into three germ layers (ectoderm, mesoderm, and endoderm). Differentiation protocols used involved hanging-drop EB formation (Schroeder et al., 2009) in which a defined number of mESCs was used to form one EB. In this way, all EBs generated would be of similar size. To make hanging-drop EBs, mESCs were maintained undifferentiated for at least three passages, followed by trypsinization and counting. Single-cell suspension containing defined mESC number (200, 500, and 600 cells/20 $\mu \mathrm{l}$ for neural, cardiac, and pancreatic differentiation, respectively) was prepared in the Differentiation Medium I consisting of Iscove's modification of DMEM (IMDM) supplemented with 20\% ESCult FBS, 1X P/S/Q, $1 \mathrm{mM}$ sodium pyruvate, $1 \mathrm{X}$ NEAA and $450 \mu \mathrm{M}$ monothioglycerol (Sigma-Aldrich). On the lid of a $100 \mathrm{~mm}$ bacteriological Petri dish, about 60 droplets $(20 \mu \mathrm{l}$ per drop) of mESC suspension were placed. $10 \mathrm{ml}$ of PBS was added to the dish. The lid was inverted and mESCs in hangingdrops were cultivated for 2-3 days. During this period, mESCs aggregated to form one EB within each droplet. Hanging-drop EBs were then incubated in suspension in the Differentiation Medium I for 2-3 days until the time of specific lineage differentiation. When collecting or transferring floating EBs, large orifice $200 \mu \mathrm{l}$ tips were used to keep EBs intact.

\section{Neural Progenitor Cell Differentiation}

Neural EBs (200 mESCs per drop) were hung for 2 days before transferring to ultra-low attachment 96-well plate and EBs were further cultivated for 3 days. One EB was placed in one well so that size and morphology could be examined under a microscope. Day 5 EBs were collected and placed into a 24-well cell culture plate for attachment. After 1 day, NSC selection was started by switching the medium to ITSFn medium, followed by NSC expansion in the N2 medium. This corresponds to Stage 3 and Stage 4 of the 5 -stage neural differentiation method described above.

\section{Cardiac Progenitor Differentiation}

Cardiac EBs (500 mESCs per drop) were hung for 3 days before transferring to a $60 \mathrm{~mm}$ bacteriological Petri dish and cultured for 2 days in suspension. Day 5 EBs were placed in gelatincoated 6-well plates (about 15 EBs per well) for attachment and differentiation in Differentiation Medium I. This was sufficient to drive cardiac differentiation as beating EBs were observed from both R1 and HN after 7 days. The medium was changed every 2 days for 2 weeks (Boheler et al., 2002; Schroeder et al., 2009).

\section{Pancreatic Progenitor Differentiation}

Pancreatic EBs (600 mESCs per drop) were hung for 3 days before transferring to a $60 \mathrm{~mm}$ bacteriological Petri dish and cultured for 2 days in suspension. Day 5 EBs were plated on gelatin-coated 6-well plates for attachment and differentiation in Differentiation Medium I. The medium was changed every 2 days for 9 days. Cells were trypsinized and seeded onto poly-L-ornithine/laminin-coated plates in the 
pancreatic differentiation medium. The medium was composed of DMEM/F12 supplemented with 1X P/S/Q, $25 \mu \mathrm{g} / \mathrm{ml}$ insulin, $50 \mu \mathrm{g} / \mathrm{ml}$ human apo-transferrin, $30 \mathrm{nM}$ selenium chloride, $20 \mathrm{nM}$ progesterone, $100 \mu \mathrm{M}$ putrescine, $1 \mu \mathrm{g} / \mathrm{ml}$ laminin, $2 \%$ $\mathrm{B} 27$ and $10 \mathrm{mM}$ nicotinamide. The medium was changed every 2 days for 3 weeks (Blyszczuk et al., 2004; Schroeder et al., 2009).

In lineage differentiation experiments, cell morphology was monitored under a microscope throughout the differentiation protocol. Cells at different stages were collected for RNA extraction and progenitor-specific markers were detected by RT-PCR.

\section{RNA Extraction, cDNA Synthesis, RT-PCR}

Total RNA was extracted using TRI-Reagent (Sigma-Aldrich) followed by DNase-I treatment (Promega). For each sample, $1 \mu \mathrm{g}$ of total RNA was used to synthesize cDNA using the First-Strand cDNA Synthesis Kit and 10X primer mix from USB (Affymetrix). qPCR was carried out on equal volumes of RT reactions using the $2 \mathrm{X} \mathrm{SYBR}^{\circledR}$ Green PCR Master Mix (Applied Biosystems). Cycling parameters used were: denaturation at $95^{\circ} \mathrm{C}$ for $30 \mathrm{~s}$, annealing at $52-60^{\circ} \mathrm{C}$ for $40 \mathrm{~s}$ depending on primers, and elongation at $72^{\circ} \mathrm{C}$ for $45 \mathrm{~s}$, for 45 cycles. qPCR data was calculated after normalization to GAPDH or $18 \mathrm{~S}$ ribosomal RNA. Primer sequences are provided in Supplementary Table 1.

\section{Western Blot Analysis}

Mouse embryonic stem cells were lysed in total lysis buffer [20 mM Tris-HCl ( $\mathrm{pH}$ 8.0), $137 \mathrm{mM} \mathrm{NaCl}, 1 \mathrm{mM}$ EDTA, $1 \%$ Triton X-100, $10 \%$ glycerol, $1.5 \mathrm{mM} \mathrm{MgCl}_{2}, 1 \mathrm{mM} \mathrm{DTT}$, $1 \mathrm{mM}$ PMSF, and 1X protease inhibitor cocktail] and cell lysate extracted by centrifugation at $13,000 \mathrm{rpm}$ for $30 \mathrm{~min}$ at $4^{\circ} \mathrm{C}$. Protein concentrations were measured by Bradford assay (BioRad). Fifty micrograms of total protein was loaded in each lane of an SDS-polyacrylamide gel.

Cytoplasmic and nuclear fractions were extracted using NEPER Nuclear and Cytoplasmic Extraction Reagents (Pierce Biotechnology). From $20 \mu \mathrm{l}$ of packed cells as starting material, about $200 \mu \mathrm{l}$ of cytoplasmic fraction and $100 \mu \mathrm{l}$ of nuclear fraction were obtained. Five percentage of total volume was loaded in each lane.

The following antibodies were used at the indicated dilution: rabbit $\alpha$-Kdm6A (1:2000, Bethyl Laboratories), rabbit $\alpha$-Olig2 (1:1000, Novus Biologicals), rabbit a-Vinculin (1:4000, Thermo Fisher Scientific), rabbit $\alpha$-YY1 (1:2000, Santa Cruz Biotechnology), IRDye 680RD goat $\alpha$-rabbit secondary antibody (1:10000, LI-COR Biosciences). Fluorescent signal was scanned using the LI-COR Odyssey machine.

\section{Statistical Analysis}

Unless stated otherwise, values in the figures and text are presented as mean \pm SEM. Statistical analysis was performed using Prism 7 (GraphPad Software). One-way analysis of variance (ANOVA) was used followed by Bartlett's test. ${ }^{* * * *} P<0.0001$ represents statistical significance.

\section{RNA-Seq}

Total RNA was isolated from three different batches of R1 and HN mESCs collected on different dates using the Directzol $^{\text {TM }}$ RNA MiniPrep Kit (Zymo Research) according to the manufacturer's instructions. Bioanalyzer was used to determine RNA concentration and quality. One hundred and thirty nanograms of total RNA was used to construct RNA-Seq libraries using Illumina TruSeq RNA Library Preparation Kit v2 and 15 cycles of PCR amplification. Libraries were run on an Illumina HiSeq 2500 instrument using a paired end 50 protocol, rapid run flow cell.

Sequencing results were demultiplexed and converted to FASTQ format using Illumina bcl2fastq software. Reads were aligned to the mouse genome (build mm10/GRCm38) using the splice-aware STAR aligner (Dobin et al., 2013). PCR duplicates were removed using the Picard toolkit ${ }^{1}$. HTSeq package (Anders et al., 2015) was utilized to generate counts for each gene based on how many aligned reads overlap its exons. These counts were then normalized and used to test for differential expression using negative binomial generalized linear models implemented by the DESeq2 R package (Love et al., 2014). Additionally, differential exon usage analysis was performed using the DEXSeq $\mathrm{R}$ package (Anders et al., 2012). The RNA-seq data has been deposited to the NCBI GEO database with an accession number GSE92905.

\section{RESULTS}

\section{mESCs Lacking Htt Fail to Differentiate into Neural Stem Cells}

We investigated potential role for wild type and mutant $\mathrm{Htt}$ in the differentiation of mESCs to cells of neural lineage. The four mESC lines tested were: wild type R1 ES cells, Htt nullizygous

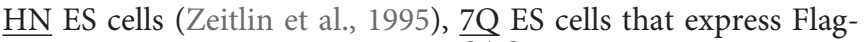
tagged wild type $\mathrm{Htt}\left(3 \mathrm{xFlag}-\mathrm{Htt}^{7 \mathrm{Q} / 7 \mathrm{Q}}\right)$, heterozygous $140 \mathrm{Q}$ ES cells carrying an allele encoding Flag-tagged expanded polyQ $\mathrm{Htt}$ (3xFlag-Htt ${ }^{140 Q / 7 Q}$ ) (Zheng et al., 2012). Expression of Htt and pluripotency markers was verified by immunoblotting and RTqPCR (Supplementary Figure 1). The R1, HN, 7Q, and 140Q ES cells were differentiated into neurons/glia using the 5-stage neural differentiation method involving generation of massive EBs (Okabe et al., 1996; Lee et al., 2000). mESCs (Stage 1) were cultured under feeder-free conditions and undifferentiated status confirmed by dark purple staining of ES colonies in the AP assay (Figure 1A). Floating EBs (Stage 2) were spontaneously generated after seeding mESCs to a non-adherent Petri dish. All four mESCs formed EBs of different sizes. HN mESCs formed EBs much smaller than other three lines (Figure 1B). After 4 days in suspension, EBs were transferred to cell culture plates for attachment and differentiation. This was the start of Stage 3, selection of nestin-positive NSCs. After 1 day in the ITSFn medium, all EBs from R1, 7Q, and 140Q lines attached and started to differentiate. However, less than half of HN EBs attached and showed little signs of differentiation (Figure 1C). Cells were cultured in ITSFn for seven more days. R1, 7Q, and

\footnotetext{
${ }^{1}$ http://broadinstitute.github.io/picard
} 
A

Stage 1: Undifferentiated mESCs
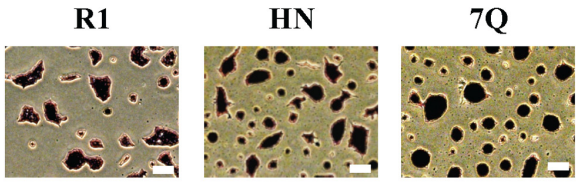

140Q

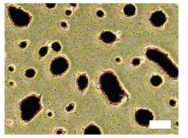

B

Stage 2: Floating EBs (Day 3)

R1

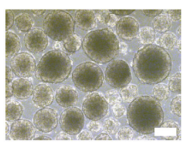

HN

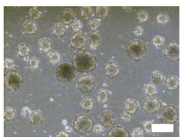

$7 \mathbf{Q}$

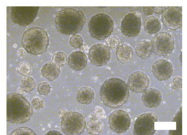

140Q

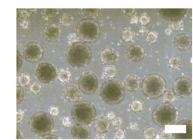

C

Stage 3: Selection of NSCs in ITSFn medium

(Day 1)

R1

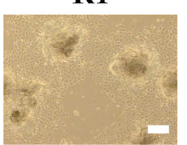

(Day 8)

R1

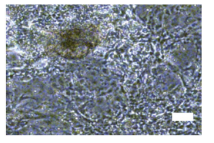

HN

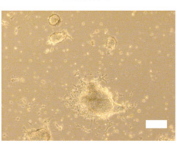

HN

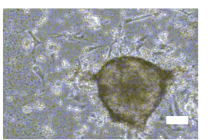

7Q

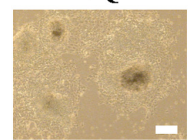

$7 Q$

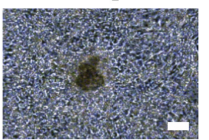

$140 Q$

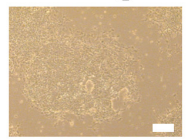

$140 Q$

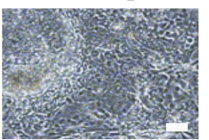

Average number of cells collected from $100 \mathrm{~mm}$ dish after Stage 3 (ITSFn Day 8)

\begin{tabular}{|c|c|}
\hline Cell line & Number of cells collected \\
\hline $\mathrm{R} 1$ & $2.5 \times 10^{7}$ \\
\hline $\mathrm{HN}$ & $3 \times 10^{6}$ \\
\hline $7 \mathrm{Q}$ & $2.53 \times 10^{7}$ \\
\hline $140 \mathrm{Q}$ & $2.57 \times 10^{7}$ \\
\hline
\end{tabular}

D

Stage 4: Expansion of nestin-positive NSCs in N2 medium (Day 6)

R1

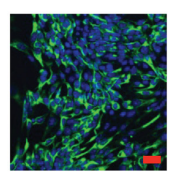

$7 \mathbf{Q}$

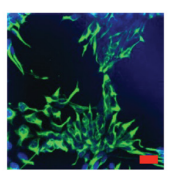

140Q
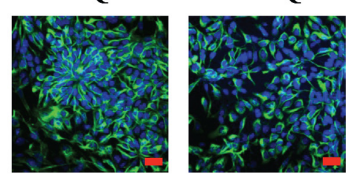

E

Stage 5: Differentiation of neurons/glia (Day 6)

R1

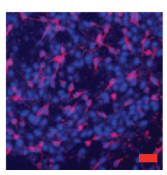

$\beta-$ III

tubulin
HN
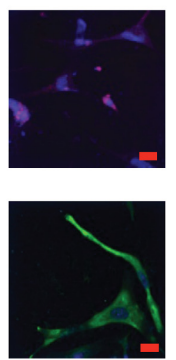

7Q
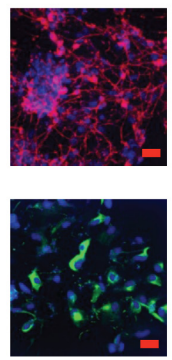
140Q (Day 4)
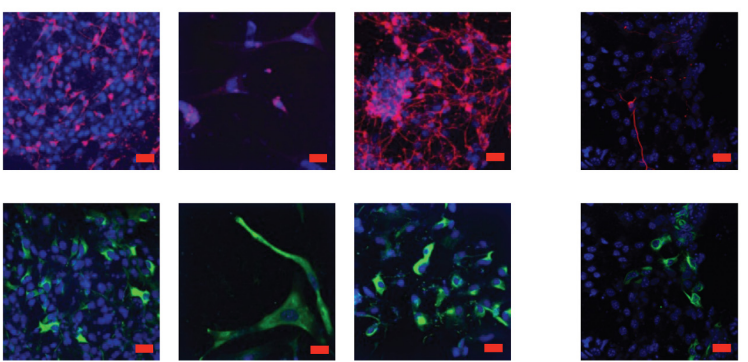

FIGURE 1 | Neural differentiation of mESC lines carrying different forms of Htt. Using the 5 -stage neural differentiation method, four mESC lines were differentiated into neurons/glia. Morphology of cells at different stages is shown. (A) Stage 1: mESCs. The pluripotency of mESCs was examined by the AP assay. (B) Stage 2: floating EBs at Day 3. (C) Stage 3: Selection of NSCs in ITSFn medium. EBs were plated onto cell culture plates for attachment and differentiation. Morphology of NSCs on Day 1 and Day 8 are shown. The average number of cells collected from one $100 \mathrm{~mm}$ dish after Stage 3 (ITSFn, Day 8) for each cell line is shown in the table. (D) Stage 4: Expansion of nestin-positive NSCs in N2 medium at Day 6. Anti-nestin (green) and TO-PRO-3 dye (blue, nuclei). (E) Stage 5: Differentiation of neurons/glia at Day 6 (R1, HN, 7Q) and Day 4 (140Q). Shown are $\beta$-III tubulin in red, GFAP in green, and TO-PRO-3 in blue. Scale bar: (A-C) $200 \mu \mathrm{m},(\mathbf{D}, \mathbf{E}) 25 \mu \mathrm{m}$. 
$140 \mathrm{Q}$ lines continued to differentiate and NSCs spread across the entire culture plate (Figure 1C, Day 8). After several rounds of changes of the ITSFn medium over 8 days, only a low percentage of HN EBs remained attached, with limited differentiation. Nestin-positive NSCs (Stage 4) were expanded by collecting and replating the Day 8 ITSFn cells into N2 medium. On average, nearly 10 -fold less cells were obtained from HN (Figure 1C; Table). After culturing for 6 days in the N2 medium, cells were stained for an NSC marker nestin. Nearly all differentiated cells expressed nestin (Figure 1D), indicating successful generation of NSCs. They were next differentiated into neurons/glia (Stage 5). A mixture of neurons ( $\beta$-III tubulin-positive) and glia (GFAPpositive) was obtained from both $\mathrm{R} 1$ and $7 \mathrm{Q}$ lines (wild type for Htt, Figure 1E). Most of HN NSCs died leaving a few large cells stained positive for GFAP. For 140Q NSCs, cell death was observed during the final stage of differentiation (Stage 5, Day 4, Figure 1E; Supplementary Figure 2), consistent with a previous report (Conforti et al., 2013). In summary, cells with wild type or mutant $\mathrm{Htt}$ (R1, 7Q, and 140Q) were able to generate NSCs, but cells lacking $\mathrm{Htt}(\mathrm{HN})$ did not make the NSCs. Further, only wild type ES cells differentiated into neurons/glia.

\section{mESCs Lacking Htt Show Limited Capacity to Form Neural Progenitor Cells}

The above results suggest a requirement for $\mathrm{Htt}$ in neural differentiation. We next employed differentiation protocols involving hanging-drop EB formation. A defined number of mESCs was used to form one EB so that all EBs generated would be of similar size (Schroeder et al., 2009). These protocols were used to produce progenitors of ectoderm, endoderm, and mesoderm lineages.

Neural progenitor cell differentiation (ectodermal lineage) was carried out in four mESC lines (Figure 2A). All made intact EBs (spheres); however, on average $\mathrm{HN}$ neural EBs were smaller in size (Figure 2B). Instead of using $60 \mathrm{~mm}$ Petri dishes, we modified the original protocol by transferring day 2 neural EBs to ultra low attachment $96-$ well plates. This way we could monitor floating EBs one by one under a microscope. For each EB, it was counted as 'formed' if it had a good spherical structure. The efficiency of EB formation, calculated as the number of EBs formed over EBs seeded, was similar for all four cell lines (around 95\%, Figure 2B). After culturing in ultra low attachment 96-well plates for 3 days, bright field images of Day 5 neural EBs were captured. All EBs generated from $\mathrm{R} 1,7 \mathrm{Q}$, and $140 \mathrm{Q}$ lines remained spherical, with an average diameter above $300 \mu \mathrm{m}$ (Figure 2C). In contrast, $\mathrm{HN}$ neural EBs were much smaller ( $50 \%$ of R1 neural EBs) and appeared disorganized in structure. Day 5 neural EBs were transferred to cell culture plates for attachment and differentiation to NSCs in ITSFn medium. On Day 1 in the ITSFn medium, almost all R1,7Q, and 140Q neural EBs attached to cell culture plates and started to differentiate. However, most HN neural EBs did not attach. Attached cells if any did not differentiate. Differentiation potential of neural EBs was calculated as the percentage of EBs attached and differentiated over the total number of EBs plated. HN neural EBs showed low efficiency of differentiation
$(<10 \%)$, while $\mathrm{R} 1,7 \mathrm{Q}$, and $140 \mathrm{Q}$ neural EBs efficiently generated NSCs (>95\%) (Figure 2D). NSC selection in ITSFn medium was carried out for 8 days. Only a few HN neural EBs attached to cell culture plates with no sign of differentiation (Figure 2D, Day 8). In contrast, neural EBs of $\mathrm{R} 1,7 \mathrm{Q}$, and $140 \mathrm{Q}$ cell lines differentiated into NSCs and occupied nearly the entire plate.

Quantitative RT-qPCR was performed for Nestin, Pax6, Oct4, $\mathrm{Htt}$ exon 16-17, and GAPDH using RNA collected from cells at different neural differentiation stages (Figure 2E; Supplementary Figure 3A). We found expression of Nestin elevated in R1, 7Q, and 140Q EBs (Day 5) and ITSFn NSCs (Day 8), but not in HN cells. Lack of Nestin induction in HN ITSFn NSCs agreed with the observation that HN was less efficient in generating NSCs compared to stem cells expressing wild type or mutant Htt. We also examined Pax6 levels during neural differentiation. In ITSFn NSCs, all four cell lines showed elevated Pax6, however, they were not statistically significant. At the mESC stage, all four cell lines showed expression of the pluripotent gene Oct4 (Supplementary Figure 3A). Upon neural differentiation to EBs and ITSFn NSCs, Oct4 mRNA levels were dramatically reduced to less than $10 \%$ for R1, 7Q, and 140Q cells. By contrast HN cells maintained relatively high Oct4 expression in EBs (34\%) and ITSFn NSCs (50\%). This is consistent with the observation that HN EBs did not readily attach and differentiate into NSCs when floating EBs were placed in cell culture plates. As expected Htt (exon 1617) expression in $\mathrm{HN}$ cells was 10 -fold less than $\mathrm{R} 1,7 \mathrm{Q}$, and $140 \mathrm{Q}$ cells at all stages of differentiation. The results suggest that HN mESCs have limited capacity in generating neural progenitor cells.

\section{mESCs Lacking Htt Can Differentiate into Pancreatic and Cardiac Progenitor Cells}

We next sought to determine whether Htt is also required for endoderm and mesoderm differentiation. Cardiac progenitor differentiation (mesodermal lineage) was carried out on R1 and HN mESCs using the hanging-drop EB method, with $500 \mathrm{mES}$ cells in each droplet (Figure 3A). At Day 4, cardiac EBs remained intact in both cell lines, although the size of $\mathrm{HN}$ cardiac EBs was smaller (Figure 3B). On Day 5, cardiac EBs were transferred to cell culture plates. Almost all EBs attached and differentiated over the following 2 weeks. Both R1 and HN mESCs differentiated into cardiac progenitor cells with similar morphology on Day 12 and Day 19 (Figure 3B). RT-qPCR analysis showed presence of cardiac progenitor-specific markers $\mathrm{Nkx} 2.5$ and $\alpha \mathrm{MHC}$ in differentiated cells (Figure 3C). Interestingly, we found expression of the markers to be greater at Day 12 in $\mathrm{HN}$ cardiac progenitors compared with Day 19 cells, while R1 cells showed induction of these two markers as mESCs differentiated to Day 12 and Day 19 cardiac EBs. The observed difference suggests Htt may play a limited role in this process. At the mESC stage, both R1 and HN cells showed expression of the pluripotent gene Oct4 (Supplementary Figure 3B). Upon cardiac progenitor cell differentiation, Oct 4 mRNA levels were greatly reduced to about $10 \%$ or less in both cell lines. Immunocytochemistry of Desmin, a specific marker expressed 
A

B

Day

ay

\begin{tabular}{|c|c|}
\hline $\begin{array}{l}\text { Hanging- } \\
\text { drop EBs } \\
\text { (200 cells/drop) }\end{array}$ & $\begin{array}{c}\text { Ultra low attachment } \\
\text { 96-well plate } \\
\text { (floating EBs) }\end{array}$ \\
\hline
\end{tabular}

Floating EBs (Day 2)

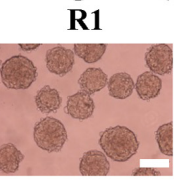

HN

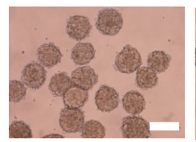

$7 \mathbf{Q}$

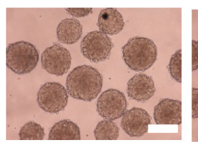

140Q

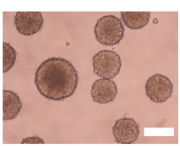

C

EBs cultured in ultra low attachment 96-well plate (Day 5)

R1

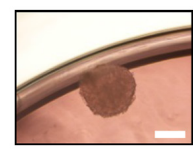

HN

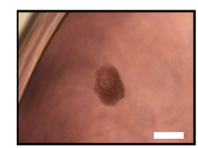

$7 Q$

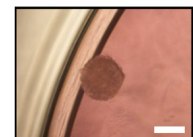

$140 Q$
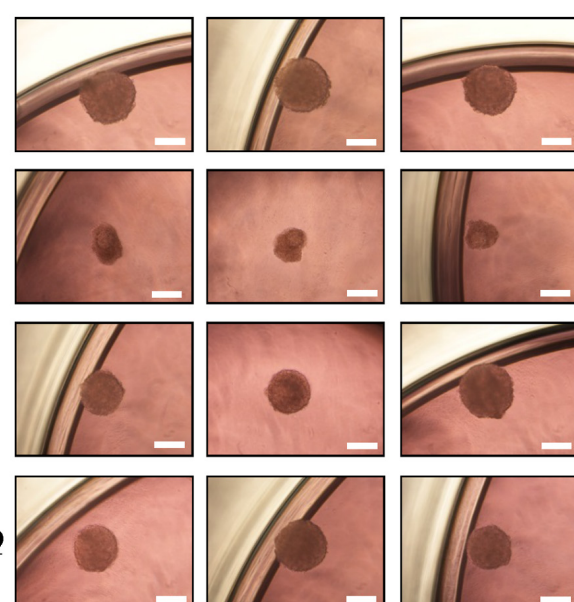

Average diameter

355.95

$\pm \mathbf{2 8 . 3 3}$
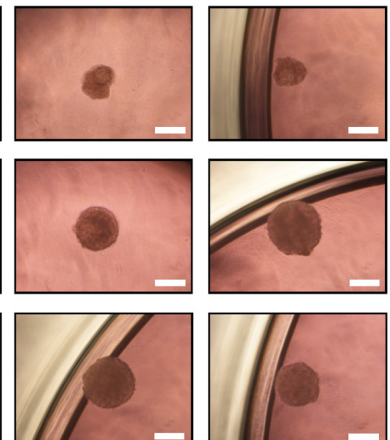

169.75

$\pm 39.34 * * * *$

300.76

$\pm \mathbf{4 9 . 7 6}$

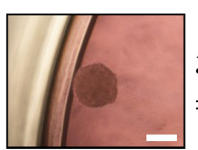

300.00

$\pm 48.74$

D

Generation of NSCs in ITSFn medium

R1

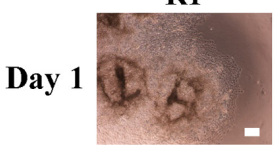

R1

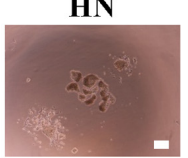

HN

Day 8

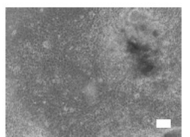

E

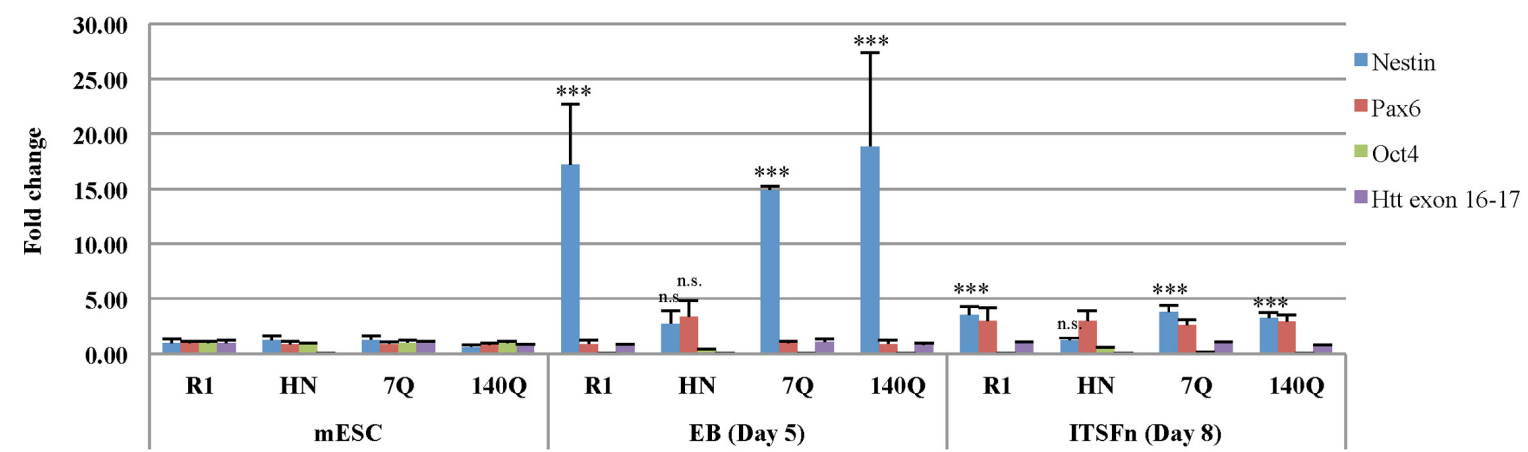

FIGURE 2 | Neural progenitor cell differentiation by the hanging-drop EB method (ectodermal lineage). (A) Diagram showing the timeline of neural progenitor differentiation. (B) Morphology of floating EBs at Day 2. Graph at right shows efficiency of EB formation, calculated as the percentage of EBs formed over the total number of EBs seeded. R1: $95.62 \pm 0.75$, HN: $91.04 \pm 7.41,7 \mathrm{Q}: 94.37 \pm 1.71,140 \mathrm{Q}: 95.88 \pm 2.88$. No statistical significance.
NSC selection in NSC expansion in N2 medium

ITSFn medium

1

Efficiency of EB formation

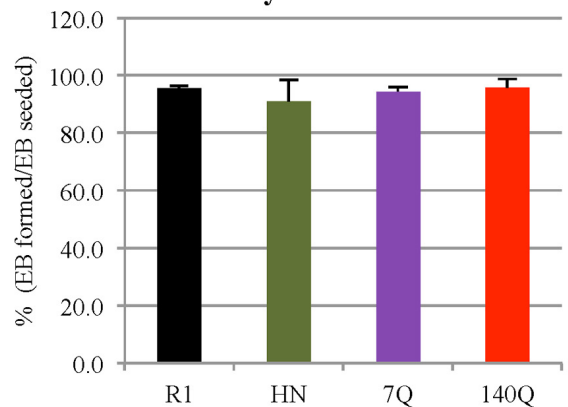

Differentiation potential of neural EBs

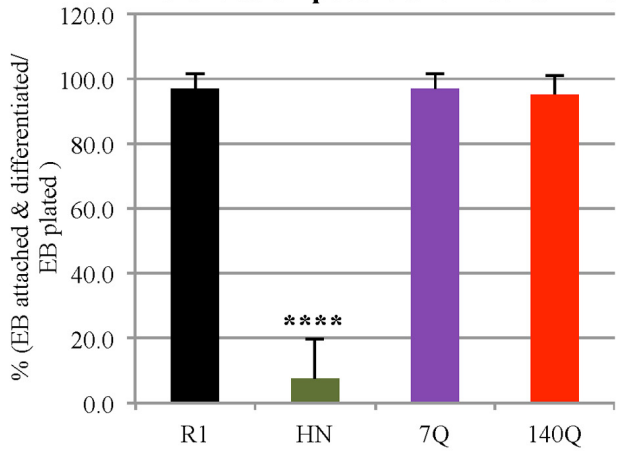




\section{FIGURE 2 | Continued}

(C) Morphology and average diameter of Day 5 EBs cultured in ultra low attachment 96 -well plate. ${ }^{* * * *} P<0.0001$, compared to R1, 7Q, and $140 \mathrm{Q}$, by one-way ANOVA test. $n=3$ independent experiments. (D) Generation of NSCs. Morphology of NSCs cultured in ITSFn medium at Day 1 and Day 8 . Differentiation potential of neural EBs was calculated as the percentage of EBs attached and differentiated over the total number of EBs plated. R1: $97.09 \pm 4.47, \mathrm{HN}$ : 7.60 $\pm 12.04,7 \mathrm{Q}$ : $97.08 \pm 4.76,140 \mathrm{Q}: 95.31 \pm 5.86$. ${ }^{* * * *} P<0.0001$, compared to R1, 7Q, and 140Q, by one-way ANOVA test. $n=3$ independent experiments. Scale bar (B-D): $200 \mu \mathrm{m}$. (E) Expression of different markers during neural progenitor cell differentiation. Quantitative RT-qPCR was performed for Nestin, Pax6, Oct4, Htt exon 16-17, and GAPDH using RNA collected from cells at different neural differentiation stages including mESC, EB (Day 5), and ITSFn (Day 8). Gene expression was calculated as fold change (over R1 mESC) after normalization to GAPDH expression. ${ }^{* * *} P<0.001$, compared to mESCs, by Dunnett's multiple comparisons test (one-way ANOVA). n.s., non-significant $(P>0.05)$. Separate graphs for Oct4 and Htt exon 16-17 are shown in Supplementary Figure 3A.

in Day 11 cardiac EBs, showed positive staining in both R1 and HN Day 12 cardiac EBs (Supplementary Figure 4). The results suggest that $\mathrm{Htt}$ is not required for cardiac progenitor cell differentiation under the experimental conditions used in this study.

Next, we carried out differentiation of R1 and HN mESCs into pancreatic progenitor cells (endodermal lineage) (Figure 4A). Similar to cardiac progenitor differentiation, pancreatic EBs formed from both cell lines, albeit those from HN EBs were smaller in size (Figure 4B). We found almost all pancreatic EBs attach and differentiate after plating Day 5 EBs onto cell culture plates. Similar morphologies were observed between $\mathrm{R} 1$ and HN differentiated cells (Figure 4B, Day 10). On Day 14, differentiated cells were collected and replated for further differentiation into pancreatic progenitors. Both R1 and $\mathrm{HN}$ cell lines gave rise to morphologically similar pancreatic progenitors as shown for Day 19 and Day 31 (Figure 4B). Quantitative RT-PCR analysis demonstrated mRNA expression of Isl1, a marker of pancreatic progenitors, in both R1 and HN differentiated cells at Day 20 and Day 35 (Figure 4C). Gcg (glucagon) is a pancreatic hormone whose expression appears at later stages of pancreatic progenitor cell differentiation. RT-qPCR data showed induction of Gcg in both R1 and HN pancreatic EBs after 20 days of differentiation. At Day 15, we observed differences in the levels of Isl1 and Gcg expression between $\mathrm{R} 1$ and $\mathrm{HN}$ cells, indicating the absence of $\mathrm{Htt}$ may have an effect on early stages of pancreatic differentiation. Nestin is also a marker during pancreatic differentiation. Its expression was found elevated dramatically in both R1 and HN EBs on Day 15 (>20-fold). Nestin levels decreased gradually as pancreatic differentiation continued. At the mESC stage, both R1 and HN cells showed expression of the pluripotent gene Oct4 (Supplementary Figure 3C). Upon pancreatic progenitor cell differentiation, Oct 4 mRNA levels were greatly reduced to about $10 \%$ in both cell lines. The results suggest that $\mathrm{Htt}$ is also not required for pancreatic progenitor cell differentiation under the experimental conditions used in this study.

In these experiments, 500 and 600 mES cells per droplet were used to generate cardiac and pancreatic EBs, respectively. Since neural EBs were made with $200 \mathrm{mESCs}$ per droplet we repeated the experiment with 500 and $1000 \mathrm{mES}$ cells per droplet (Supplementary Figure 5). We observed HN Day 5 neural EBs slightly larger when the cell number increased from 500 to 1000 per droplet. However, they remained disorganized similar to $\mathrm{HN}$ neural EBs that were generated from 200 cells per droplet. Further differentiation in ITSFn medium (Day 1 and Day 6) showed that HN neural EBs from 500 or 1000 cells per droplet did not attach and differentiate into NSCs efficiently. Therefore, increasing the starting number of mESCs to generate neural EBs did not alter the poor efficiency of $\mathrm{Htt}$-null cells in generating NSCs.

\section{Transcriptional Profiles of R1 and HN mESCs by RNA-Seq}

The neural differentiation experiments showed inefficient generation of NSCs from HN mESCs, suggesting Htt plays a critical role in this process. To investigate the basis for the lack of neural differentiation we carried out gene expression profiling by RNA-seq to examine if genes involved in neural differentiation were dysregulated in HN mESCs.

Using RNA isolated from undifferentiated $\mathrm{R} 1$ and $\mathrm{HN}$ mESCs, we performed 50 nucleotide paired-end total mRNA sequencing. Comparison of expression profiles between $\mathrm{HN}$ and R1 mESCs identified 51 up-regulated genes (log2 fold change $>1, p<0.05$ ) and 48 down-regulated genes (log2 fold change $<-1, p<0.05)$. Tables 1 and 2 show top 20 upregulated and down-regulated genes in HN mESCs. Validation of the RNA-seq data carried out by RT-qPCR demonstrated elevated expression of Olig2, Olig1, Nod1, Crisp1, and Sdc2 in HN mESCs (Figure 5A), while Maoa, Kdm6a, Fundc1, Ly6a, and Myof mRNA levels were found reduced in HN mESCs (Figure 5B). Immunoblotting confirmed increased levels of Olig2 protein and reduced levels of Kdm6a protein in the nucleus (Figure 5C).

We used Gene Set Enrichment Analysis (Mootha et al., 2003; Subramanian et al., 2005) to compare up-regulated genes in $\mathrm{HN}$ mESCs with curated gene sets within the C2 collection of the Molecular Signatures Database (Subramanian et al., 2005). We found most enriched signature "Genes up-regulated in mouse ES cells with deficient SUZ12" (Table 3). SUZ12 is a component of Polycomb Repressive Complex 2 (PRC2). Interestingly, Olig2, reported repressed by PRC1 and PRC2 in mESCs (Boyer et al., 2006), is derepressed in HN mESCs (Figure 5A; Table 1). Because there was a published report suggesting a link between $\mathrm{Htt}$ and components of the PRC2 complex (Seong et al., 2010), we asked whether Htt repressed the activation of Olig1 and Olig2 genes through the PRC2 complex. We performed chromatin immunoprecipitation analysis in $\mathrm{R} 1 \mathrm{mESCs}$ and failed to detect co-occupancy of Htt and Ezh2 (component of PRC2) at the Olig1 and Olig2 promoter regions (Supplementary Figure 6). 
A

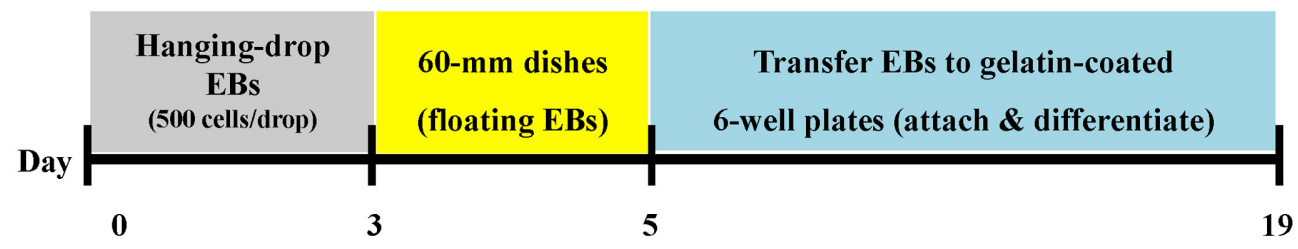

B

Day 4 Day $12 \quad$ Day 19

$\mathbf{R} 1$

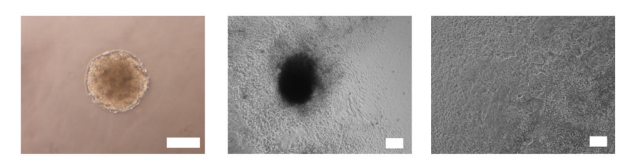

HN
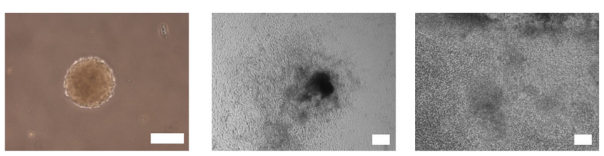

C

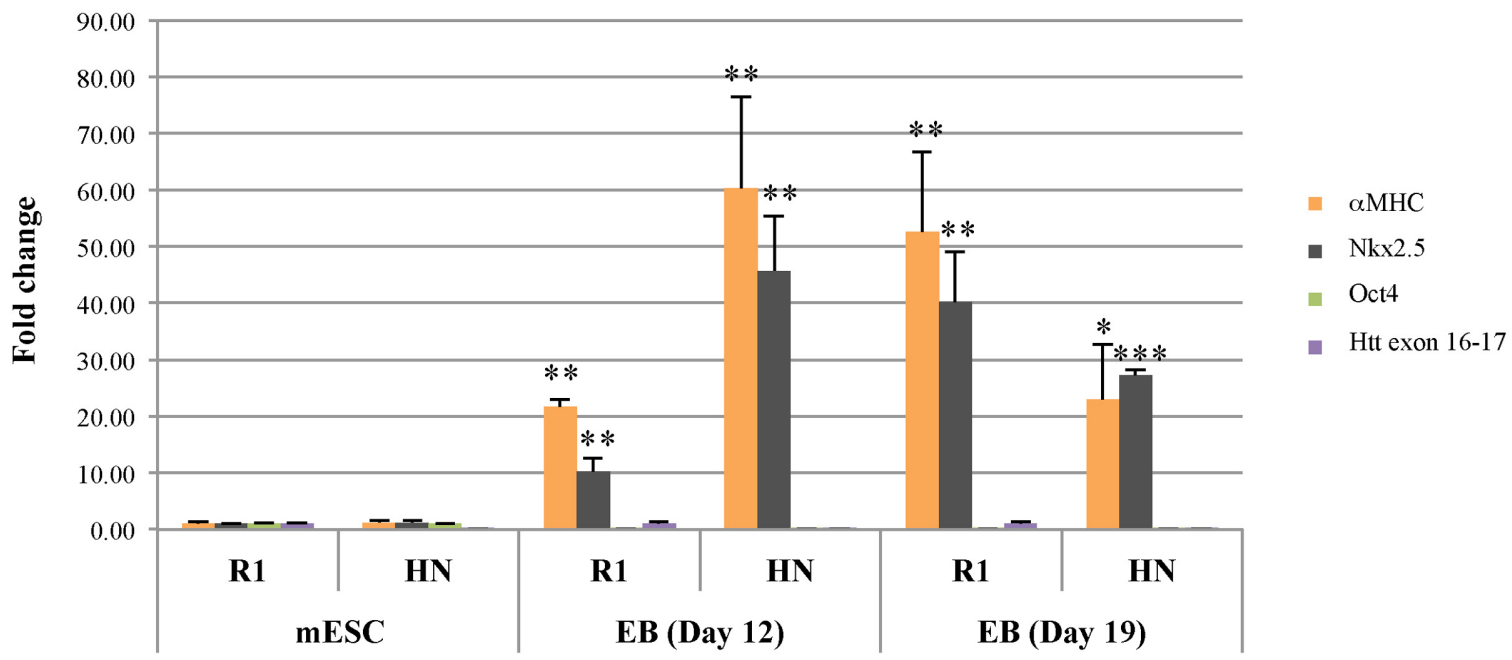

FIGURE 3 | Cardiac progenitor cell differentiation by the hanging-drop EB method (mesodermal lineage). (A) Diagram showing the timeline of cardiac progenitor differentiation. (B) Morphology of R1 and HN cells during cardiac progenitor differentiation. Scale bar: $200 \mu \mathrm{m}$. (C) mRNA expression of cardiac progenitor cell-specific markers aMHC and Nkx2.5 at Day 12 and 19 was determined by quantitative RT-qPCR. Gene expression was calculated as fold change (over R1 mESC) after normalization to GAPDH expression. ${ }^{* * *} P<0.001$, ${ }^{* *} P<0.01$, and ${ }^{*} P<0.05$, compared to the mESC group by Dunnett's multiple comparisons test (one-way ANOVA). Separate graphs for Oct4 and Htt exon 16-17 are shown in Supplementary Figure 3B.

\section{DISCUSSION}

\section{Phenotypic Differences between Wild Type and Mutant Htt in Neural Differentiation}

In this study, we examined a role of Htt in neural differentiation in vitro using the 5-stage neural differentiation method in four mESC lines carrying different forms of Htt. Our data show that
$\mathrm{Htt}$ is required for neural differentiation of mESCs. Htt is not needed for mesoderm or endoderm progenitor differentiation. RNA-seq analysis shows candidate dysregulated genes that may be involved in the inefficient NSC generation in mESCs lacking Htt.

Compared to wild type or mutant Htt-expressing cell lines (R1, 7Q, and 140Q), Htt nullizygous mESCs are not prone to generating NSCs as shown by small EB size and low tendency to attach to a plate and differentiate into NSCs. Further 
A

subculture

A

\begin{tabular}{c|c|c|c|c|}
$\begin{array}{c}\text { Hanging- } \\
\text { drop EBs } \\
\text { (600 cells/drop) }\end{array}$ & $\begin{array}{c}\text { 60-mm dishes } \\
\text { (floating EBs) }\end{array}$ & $\begin{array}{c}\text { Transfer EBs to gelatin- } \\
\text { coated 6-well plates } \\
\text { (attach \& differentiate) }\end{array}$ & $\begin{array}{c}\text { Pancreatic differentiation medium } \\
\text { (on PLO/lam-coated plates) }\end{array}$ \\
\hline 0 & 3 & 5 & 14 & 35
\end{tabular}

B

$\mathbf{R} 1$

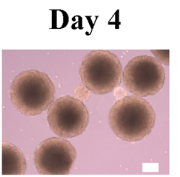

Day 10

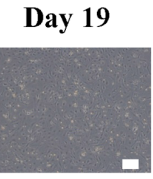

Day 31
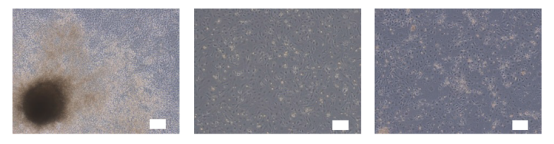

HN
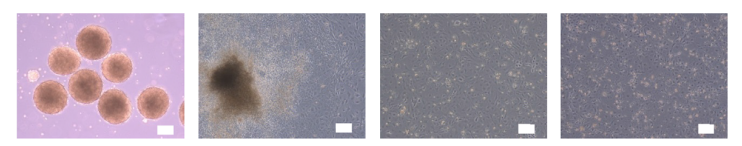

C

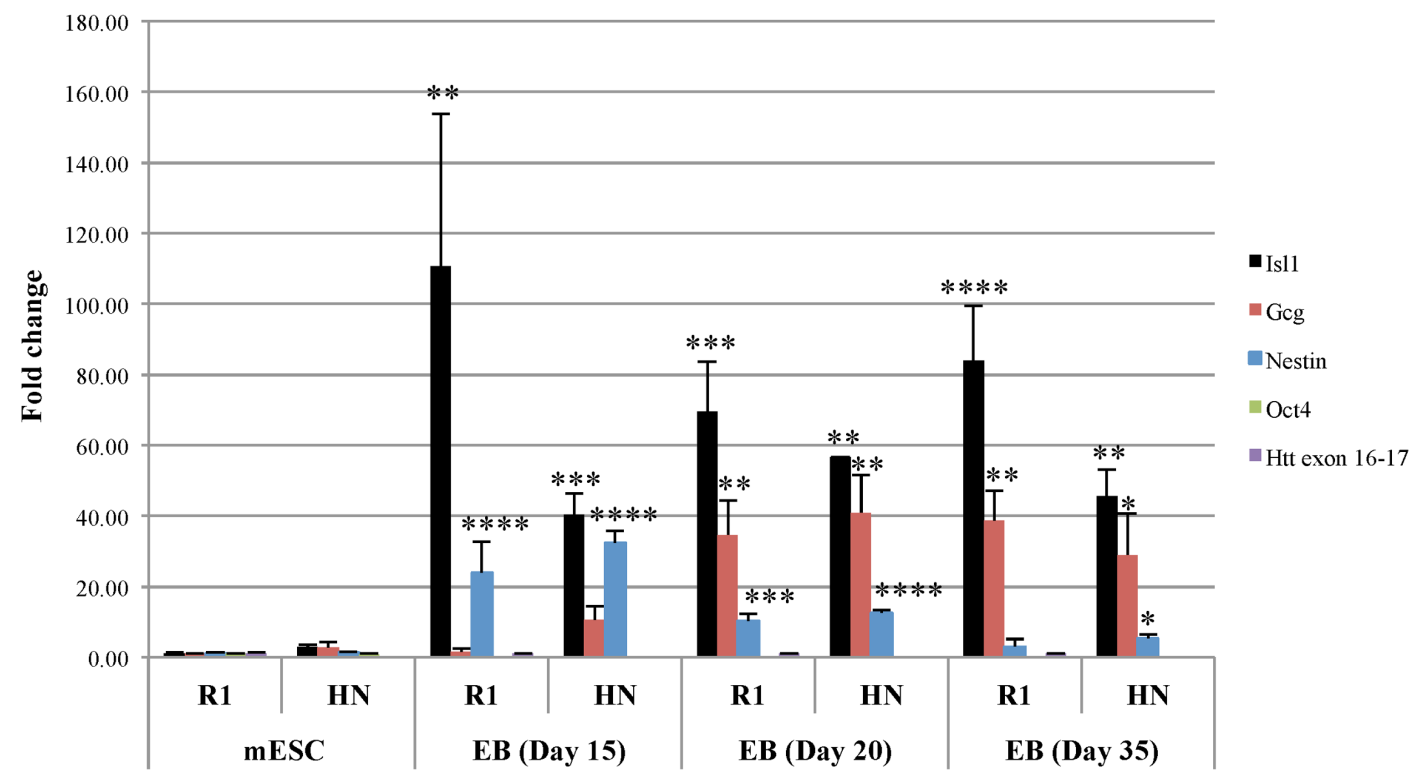

FIGURE 4 | Pancreatic progenitor cell differentiation by the hanging-drop EB method (endodermal lineage). (A) Diagram showing the timeline of pancreatic progenitor differentiation. (B) Morphology of R1 and HN cells during pancreatic progenitor differentiation. Scale bar: $200 \mu \mathrm{m}$. (C) mRNA expression of pancreatic progenitor cell-specific marker IsI1 and Gcg at Day 15, 20, and 35 was determined by quantitative RT-qPCR. Gene expression was calculated as fold change (over R1 mESC) after normalization to GAPDH expression. ${ }^{* * * *} P<0.0001,{ }^{* * *} P<0.001,{ }^{* *} P<0.01$, and $* P<0.05$, compared to the mESC group by Dunnett's multiple comparisons test (one-way ANOVA). Separate graphs for Oct4 and Htt exon 16-17 are shown in Supplementary Figure 3C.

differentiation of HN NSCs to neurons/glia resulted in massive cell loss and formation of a few giant GFAP-positive cells. This observation is consistent with a recent report demonstrating that absence of $\mathrm{Htt}$ in mESCs promotes NSC differentiation into glial cell fate (Conforti et al., 2013). This conclusion is based on the increase of GFAP-positive cells at the terminal neuronal differentiation stage. In their report, both wild type and $\mathrm{Htt}$-null ES cells generated similar numbers of NSCs. However, our data show that HN mESCs have limited capacity for generating
NSCs. The discrepancy may be explained by different neural differentiation protocols used. Conforti et al. (2013) used a monolayer differentiation method (Spiliotopoulos et al., 2009), while we adopted the 5 -stage neural differentiation protocol involving EB formation.

In contrast, neural EBs expressing mutant $\mathrm{Htt}(140 \mathrm{Q})$ attached more readily to plates and differentiated into NSCs. Further differentiation of $140 \mathrm{Q}$ NSCs into neurons/glia resulted in cell death. These results agree with studies demonstrating that 
TABLE 1 | Top 20 up-regulated genes in Htt-null mESCs (HN compared with R1).

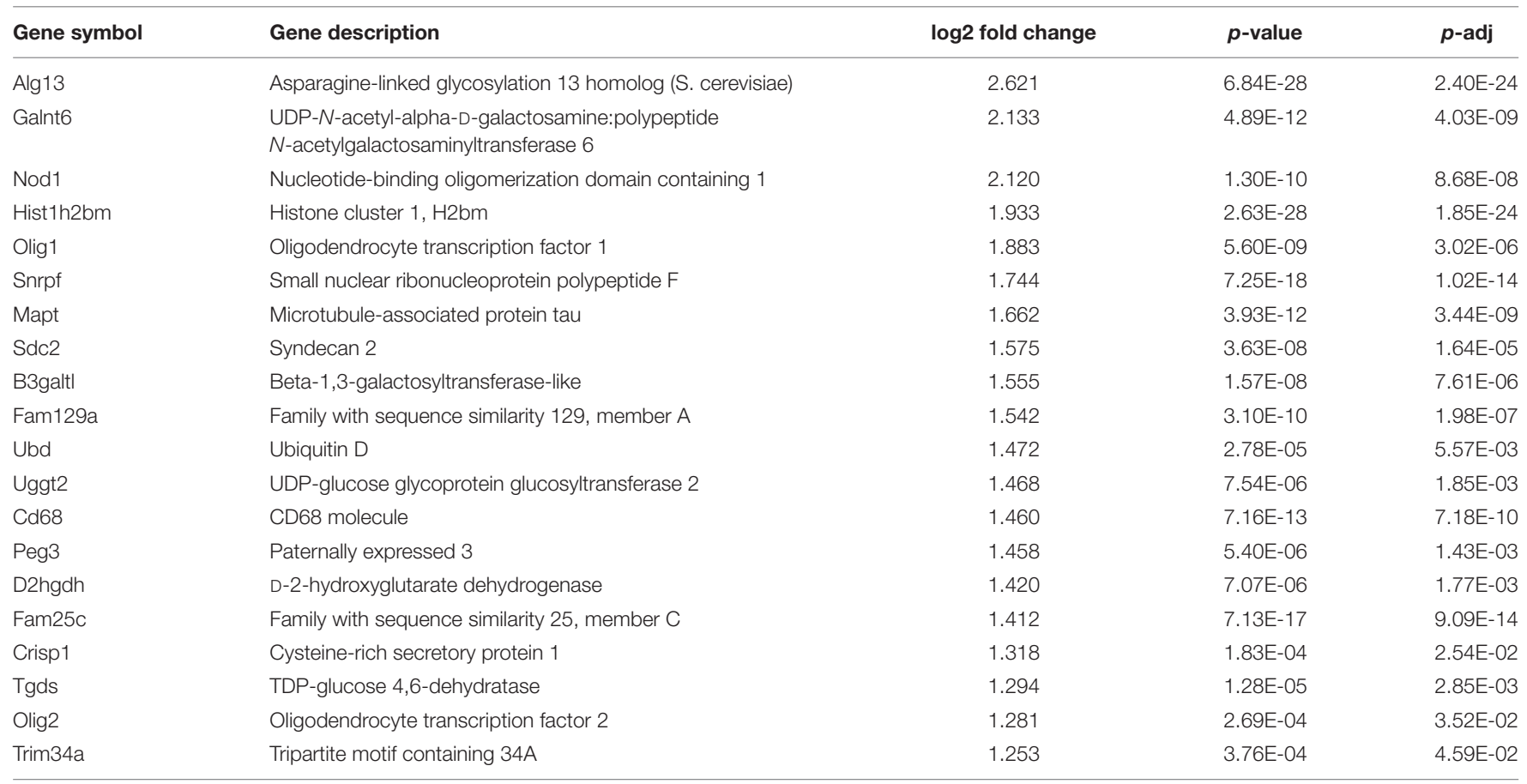

presence of polyQ-expanded Htt increases neural differentiation of embryonic and NSCs (Lorincz and Zawistowski, 2009), and cells with mutant polyQ Htt undergo cell death during neuronal differentiation (Conforti et al., 2013).

Studies by Nguyen et al. (2013b) found Htt-KO ESCs to be impaired for survival and specification of all three germ layers during EB formation and under inductive conditions, suggesting
Htt is required for neural and non-neural differentiation. In contrast, mutant $\mathrm{Htt}$-expressing cells showed alterations in stagespecific developmental events. The HN ESCs we examined were defective for differentiation into neural lineage, but not cardiac or pancreatic lineages. The $\mathrm{Htt}$-KO ESCs used by above authors are deleted of exons 4 and 5 in the murine Htt gene (Duyao et al., 1995). The HN ESCs used in this study were

TABLE 2 | Top 20 down-regulated genes in Htt-null mESCs (HN compared with R1).

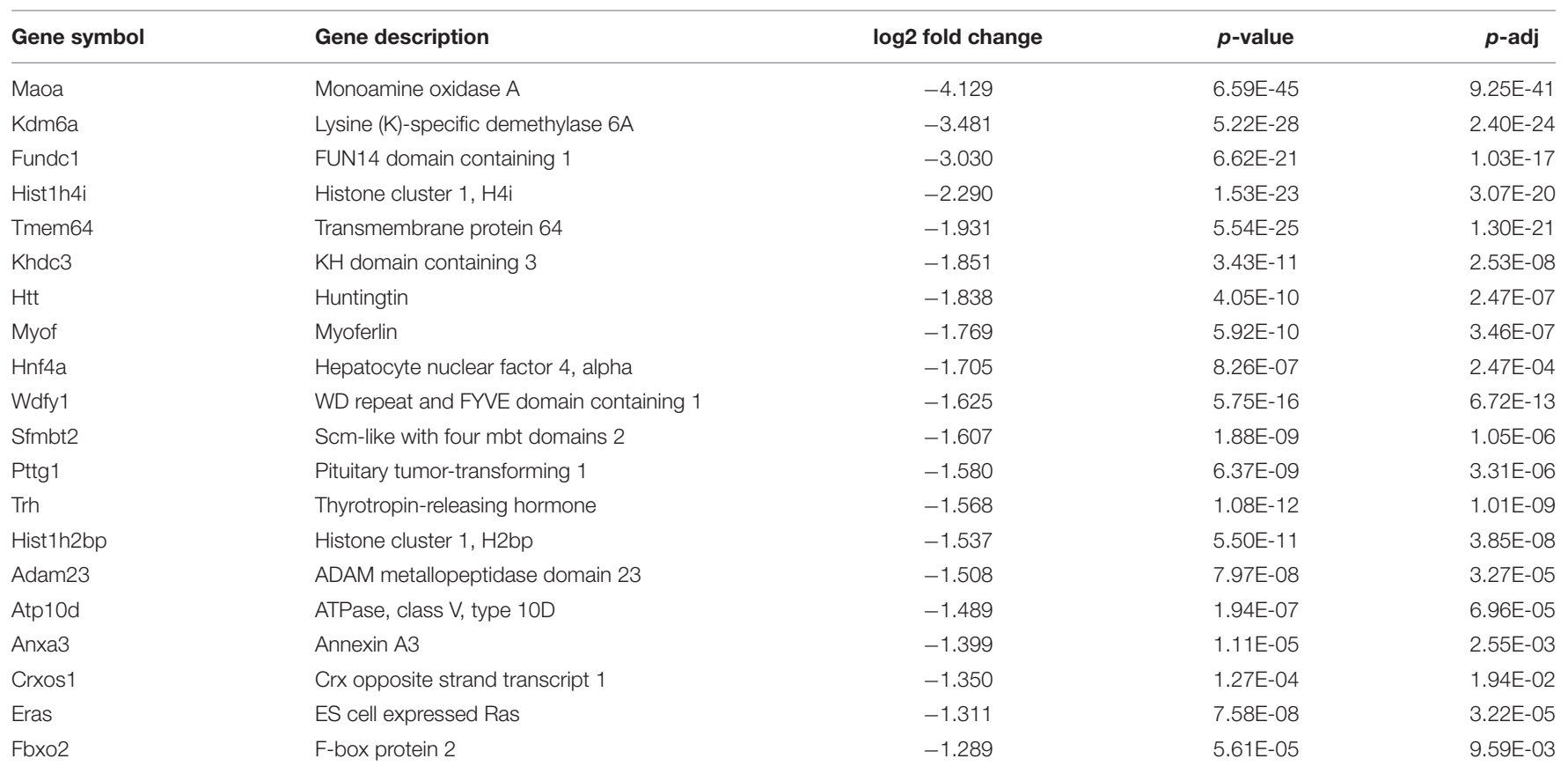


A

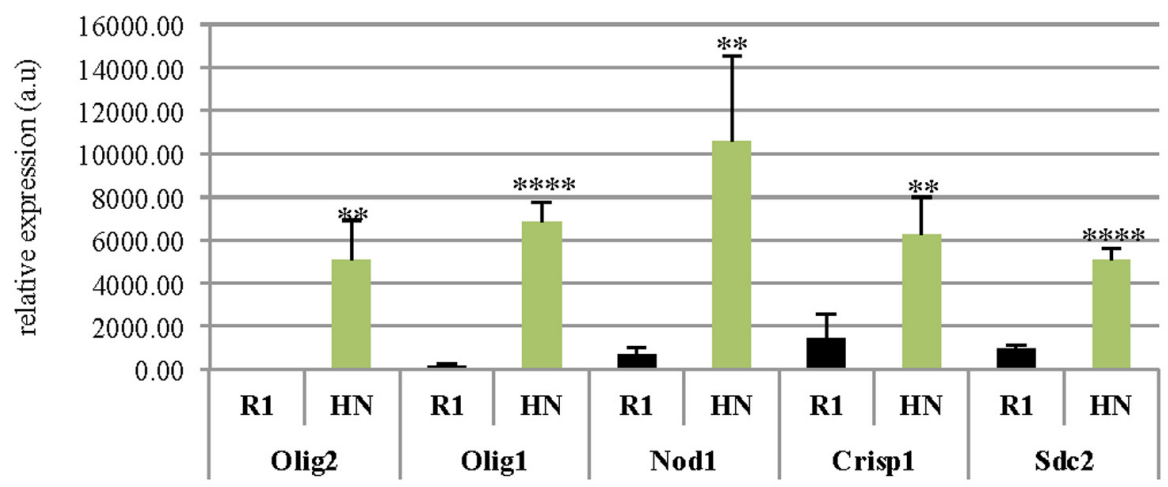

B

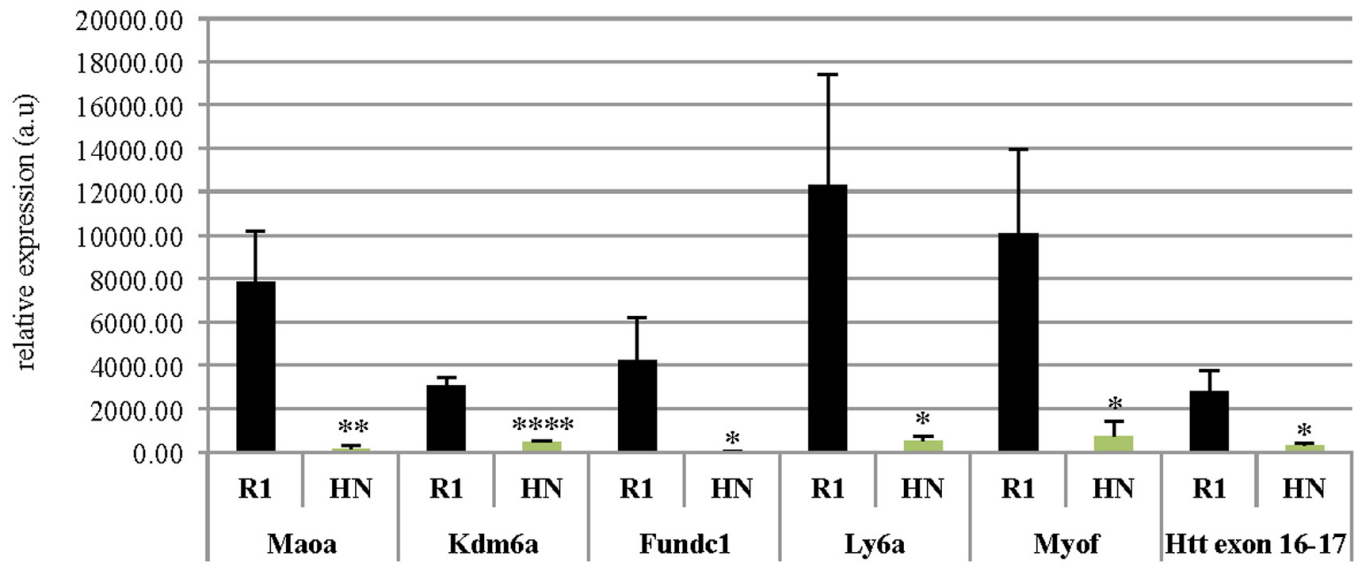

C

$\frac{\text { Cytoplasmic }}{\text { R1 HN }} \frac{\text { Nuclear }}{\text { R1 HN }}$

Kdm6a

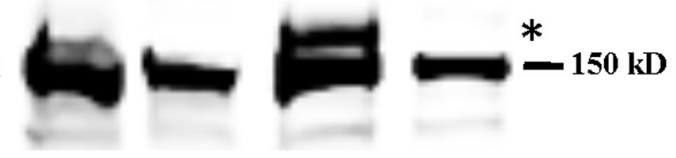

Olig2

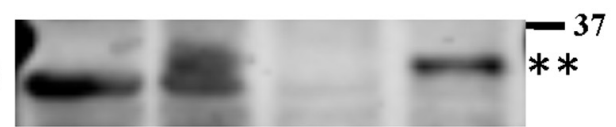

\section{Vinculin}

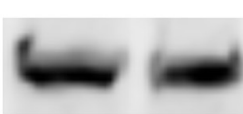

YY1

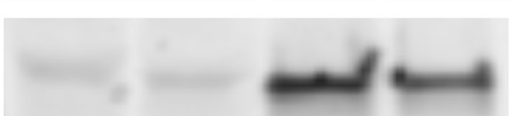

FIGURE 5 | Differentially expressed genes in R1 and Htt-null mESCs. mRNA levels of genes (A) up-regulated or (B) down-regulated in HN mESCs compared with R1 cells were confirmed by quantitative RT-qPCR. Gene expression was calculated as relative expression after normalization to18S rRNA. All experiments were carried out using RNA samples extracted from four different batches of R1 and HN mESCs $(N=4)$. ${ }^{* * * *} P<0.0001$, ${ }^{* *} P<0.01$, and ${ }^{*} P<0.05$, compared to R1, by unpaired $t$-test. a.u., arbitrary units. (C) Protein levels of Olig2 and Kdm6a were examined by immunoblotting. Vinculin and YY1 served as markers of cytoplasmic and nuclear fractions, respectively. ${ }^{*} \mathrm{Kdm} 6 \mathrm{a}(170 \mathrm{kD}),{ }^{* *} \mathrm{Olig} 2$ (32 kD). 
TABLE 3 | Gene Set Enrichment Analysis finds ES cells with deficient SUZ12 share similar enriched signatures of up-regulated genes with Htt-null mESCs.

\begin{tabular}{|c|c|c|c|c|c|c|}
\hline Gene Set Name & \# Genes in Gene Set (K) & Description & \# Genes in Overlap (k) & $\mathrm{k} / \mathrm{K}$ & $p$-value & FDR $q$-value \\
\hline PASINI_SUZ12_TARGETS_UP & 112 & $\begin{array}{c}\text { Genes up-regulated in ES (embryonic } \\
\text { stem cells) with deficient SUZ12 } \\
\text { [GenelD }=23512]\end{array}$ & 15 & 0.1339 & $9.54 \mathrm{E}-18$ & $4.51 \mathrm{E}-14$ \\
\hline
\end{tabular}

\begin{tabular}{lllll}
\hline HTRA1 & LAPTM5 & NROB1 & NFATC2IP & C17orf48 \\
SPP1 & LAMA1 & H19 & RPP25 & CYCTP \\
TMEM40 & PRDM14 & AQP3 & C17orf96 & TEX15
\end{tabular}

List of overlapping genes are shown above.

created by deleting the promoter and exon 1 sequence of $\mathrm{Htt}$ (Zeitlin et al., 1995). Our 5-stage differentiation protocol also differed from the neural induction protocol used by Nguyen et al. (2013b). These differences may account for the different outcomes of ESCs undergoing differentiation. At a molecular level we observed differences in mRNA expression of cardiac and pancreatic progenitor markers between wild type and $\mathrm{Htt}$ null cells. Thus, Htt appears to play a role in the pattern of gene expression through different stages of differentiation of cardiac and pancreatic progenitors.

\section{Transcriptional Profiling of mESCs Lacking $\mathrm{Htt}$}

The most down regulated gene in Htt null cells is MaoA, an enzyme that degrades amine neurotransmitters such as serotonin, dopamine, and noradrenalin. Its deficiency causes excess production of monoamine neurotransmitters resulting in enhanced aggressiveness in mice and humans (Brunner et al., 1993; Alia-Klein et al., 2008). Changes in the dopaminergic system have been correlated with HD pathogenesis (Chen et al., 2013; Schwab et al., 2015). Using well characterized immortalized mouse striatal cell lines STHdh ${ }^{\mathrm{Q} 7 / \mathrm{Q} 7}$ and STHdh $h^{\mathrm{Q} 111 / \mathrm{Q} 111}$, MaoA expression and activity were found elevated in cells expressing mutant Q111 Htt (Ooi et al., 2015). STHdh Q111/Q111 cells also showed enhanced susceptibility to stress and cell death. Interestingly, a recent study found polymorphisms in the MAOA gene as modifiers of psychiatric and cognitive symptoms in HD patients (Vinther-Jensen et al., 2016). MaoA may play a regulatory role in neural differentiation as mouse ES cells lacking $M a o A$ show reduced differentiation to neural cells compared to wild type (Wang et al., 2011). Similar mechanisms may be responsible for the poor neural differentiation of $\mathrm{Htt}$-null ES cells reported in this study.

Oligodendrocyte transcription factor 1 and 2 (Olig1 and Olig2) are basic helix-loop-helix transcription factors that promote oligodendrocyte specification in early neural progenitor cells. They were found up regulated in HN cells. It has been shown that Olig2 is repressed by polycomb repressive complexes in mESCs (Boyer et al., 2006). In a transgenic mouse model in which Olig2 was overexpressed in NSCs, severe defects in brain development and massive neuronal cell death of cortical progenitors were observed (Liu et al., 2015). Olig2 was shown to target enhancers of neurogenic genes and inhibit cortical neurogenesis. A recent mouse study revealed that Brg1, a subunit of the SWI/SNF chromatin remodeling complex, interacts with the Olig2 promoter and represses Olig2 expression in the cortex (Matsumoto et al., 2016). Although Brg1-null neural progenitor cells show early expression of Olig2 in the cortex, they fail to differentiate into oligodendrocyte progenitors. These studies suggest elevated levels of Olig2 in neural progenitor cells cause dysregulated neurogenesis or neuronal cell death.

A previous study examined gene expression profiles of mESCs with and without Htt (Strehlow et al., 2007). Microarray analysis showed diminished expression of vital patterning genes including Lefty1, Otx2, and Pem (Rhox5), as well as increased lysosomal activity genes such as Casp8 and Psmd8 in Htt-null mESCs (by at least twofold). We also found similar expression patterns of these genes in HN mESCs; however, fold changes were minimal (less than twofold). Although HN mESCs are the same in both studies, differences in gene expression profiling may be due to cell culture conditions and analytical methods used. We adopted the " $3 i+$ mLIF" formula to maintain the pluripotency of mESCs (Ying et al., 2008). Two additional studies reported RNA profiling of Htt-null cells by microarray (Jacobsen et al., 2011) and RNAseq (Biagioli et al., 2015). We compared our RNA-seq data with the microarray study; however, we did not find any overlapping genes dysregulated by at least twofold. As mentioned above an important difference is that the cell line used in their study was the Htt-dKO ESCs (exon 4/5 deletion), while the HN ESCs used in our study were deleted of the promoter and exon 1 sequence. There may exist subtle molecular differences between the two cell lines.

We used Gene Set Enrichment Analysis to compare up-regulated genes in HN ESCs with curated gene sets in the Molecular Signatures Database. The most enriched signature was found in the up-regulated genes in mouse ES cells deficient of SUZ12, a component of the PRC2 repressor complex (Table 3). A link between PRC2 and HD has been reported. A recent genome-wide ChIP study for the H3K4me3 histone mark found altered enrichment in postmortem prefrontal cortex of HD patient samples compared with control brains (Dong et al., 2015). They also reported depletion of the PRC2 repressive state in H3K4me3-enriched peaks in $\mathrm{HD}$, suggesting epigenetic modifications contribute to 
dysregulated gene expression associated with neurodegeneration. Further, PRC2 deficiency in striatal neurons resulted in transcriptional changes leading to neurodegeneration in mice (von Schimmelmann et al., 2016). Although PRC2 has been shown to be a direct target of Htt (Seong et al., 2010), we did not detect co-occupancy of Htt and Ezh2 (component of PRC2) at Olig1 and Olig2 promoter regions. Nevertheless, the finding that the transcriptional profile of $\mathrm{Htt}$-null ES cells is most similar to that of cells lacking a PRC2 component lends further support to the idea that epigenetic gene regulation plays a role in $\mathrm{HD}$ pathogenesis.

\section{AUTHOR CONTRIBUTIONS}

MSY and NT conceived the study and designed the experiments, MSY performed the experiments and evaluated the data, MSY and NT wrote the paper.

\section{FUNDING}

This work was supported by National Institutes of Health Grant R01 NS061917 (to NT) and by a grant from the CHDI

\section{REFERENCES}

Alia-Klein, N., Goldstein, R. Z., Kriplani, A., Logan, J., Tomasi, D., Williams, B., et al. (2008). Brain monoamine oxidase A activity predicts trait aggression. J. Neurosci. 28, 5099-5104. doi: 10.1523/JNEUROSCI.0925-08.2008

Anders, S., Pyl, P. T., and Huber, W. (2015). HTSeq-a Python framework to work with high-throughput sequencing data. Bioinformatics 31, 166-169. doi: 10.1093/bioinformatics/btu638

Anders, S., Reyes, A., and Huber, W. (2012). Detecting differential usage of exons from RNA-seq data. Genome Res. 22, 2008-2017. doi: 10.1101/gr.133744.111

Arteaga-Bracho, E. E., Gulinello, M., Winchester, M. L., Pichamoorthy, N., Petronglo, J. R., Zambrano, A. D., et al. (2016). Postnatal and adult consequences of loss of huntingtin during development: implications for Huntington's disease. Neurobiol. Dis. 96, 144-155. doi: 10.1016/j.nbd.2016. 09.006

Batista, C. M., Kippin, T. E., Willaime-Morawek, S., Shimabukuro, M. K., Akamatsu, W., and van der Kooy, D. (2006). A progressive and cell nonautonomous increase in striatal neural stem cells in the Huntington's disease R6/2 mouse. J. Neurosci. 26, 10452-10460. doi: 10.1523/JNEUROSCI.2850-06. 2006

Biagioli, M., Ferrari, F., Mendenhall, E. M., Zhang, Y., Erdin, S., Vijayvargia, R., et al. (2015). Htt CAG repeat expansion confers pleiotropic gains of mutant huntingtin function in chromatin regulation. Hum. Mol. Genet. 24, 2442-2457. doi: $10.1093 / \mathrm{hmg} / \mathrm{ddv} 006$

Blyszczuk, P., Asbrand, C., Rozzo, A., Kania, G., St-Onge, L., Rupnik, M., et al. (2004). Embryonic stem cells differentiate into insulin-producing cells without selection of nestin-expressing cells. Int. J. Dev. Biol. 48, 1095-1104. doi: 10.1387/ ijdb.041904pb

Boheler, K. R., Czyz, J., Tweedie, D., Yang, H. T., Anisimov, S. V., and Wobus, A. M. (2002). Differentiation of pluripotent embryonic stem cells into cardiomyocytes. Circ. Res. 91, 189-201.

Boyer, L. A., Plath, K., Zeitlinger, J., Brambrink, T., Medeiros, L. A., Lee, T. I., et al. (2006). Polycomb complexes repress developmental regulators in murine embryonic stem cells. Nature 441, 349-353. doi: 10.1038/nature04733

Brunner, H. G., Nelen, M., Breakefield, X. O., Ropers, H. H., and van Oost, B. A. (1993). Abnormal behavior associated with a point mutation in the structural gene for monoamine oxidase A. Science 262, 578-580.
Foundation, Inc. (to NT). MSY was a recipient of Jan Vilcek Endowment Fellowship.

\section{ACKNOWLEDGMENTS}

We thank Scott O. Zeitlin for the generous gift of mES cell lines. We acknowledge John Beckford, Sanket Aggarwal, James Stafford, Ozkur Oksuz, Igor Dolgalev, and Adriana Heguy for providing expert technical assistance. We appreciate the advice of Lisa Dailey, Matthew Murtha, Upal BasuRoy, Chris Parkhurst, Jianhua Chu, David-Emlyn Parfitt on culturing ES cells. We are grateful to Brady Culver, Iryna Berezniuk, Dimitris Placantonakis, Sumru Bayin, Aram Modrek, and Chee Wai Chua for helpful suggestions throughout the study.

\section{SUPPLEMENTARY MATERIAL}

The Supplementary Material for this article can be found online at: http://journal.frontiersin.org/article/10.3389/fncel. 2017.00033/full\#supplementary-material

Chen, J. Y., Wang, E. A., Cepeda, C., and Levine, M. S. (2013). Dopamine imbalance in Huntington's disease: a mechanism for the lack of behavioral flexibility. Front. Neurosci. 7:114. doi: 10.3389/fnins.2013.00114

Conforti, P., Camnasio, S., Mutti, C., Valenza, M., Thompson, M., Fossale, E., et al. (2013). Lack of huntingtin promotes neural stem cells differentiation into glial cells while neurons expressing huntingtin with expanded polyglutamine tracts undergo cell death. Neurobiol. Dis. 50, 160-170. doi: 10.1016/j.nbd.2012.10.015

Curtis, M. A., Penney, E. B., Pearson, A. G., van Roon-Mom, W. M., Butterworth, N. J., Dragunow, M., et al. (2003). Increased cell proliferation and neurogenesis in the adult human Huntington's disease brain. Proc. Natl. Acad. Sci. U.S.A. 100, 9023-9027. doi: 10.1073/pnas.1532244100

Dobin, A., Davis, C. A., Schlesinger, F., Drenkow, J., Zaleski, C., Jha, S., et al. (2013). STAR: ultrafast universal RNA-seq aligner. Bioinformatics 29, 15-21. doi: 10.1093/bioinformatics/bts635

Dong, X., Tsuji, J., Labadorf, A., Roussos, P., Chen, J. F., Myers, R. H., et al. (2015). The role of $\mathrm{H} 3 \mathrm{~K} 4 \mathrm{me} 3$ in transcriptional regulation is altered in Huntington's disease. PLoS ONE 10:e0144398. doi: 10.1371/journal.pone.0144398

Dunah, A. W., Jeong, H., Griffin, A., Kim, Y. M., Standaert, D. G., Hersch, S. M., et al. (2002). Sp1 and TAFII130 transcriptional activity disrupted in early Huntington's disease. Science 296, 2238-2243. doi: 10.1126/science.1072613

Duyao, M. P., Auerbach, A. B., Ryan, A., Persichetti, F., Barnes, G. T., McNeil, S. M., et al. (1995). Inactivation of the mouse Huntington's disease gene homolog Hdh. Science 269, 407-410.

Elias, S., Thion, M. S., Yu, H., Sousa, C. M., Lasgi, C., Morin, X., et al. (2014). Huntingtin regulates mammary stem cell division and differentiation. Stem Cell Reports 2, 491-506. doi: 10.1016/j.stemcr.2014.02.011

Gauthier, L. R., Charrin, B. C., Borrell-Pages, M., Dompierre, J. P., Rangone, H., Cordelieres, F. P., et al. (2004). Huntingtin controls neurotrophic support and survival of neurons by enhancing BDNF vesicular transport along microtubules. Cell 118, 127-138. doi: 10.1016/j.cell.2004.06.018

Gil, J. M., Mohapel, P., Araujo, I. M., Popovic, N., Li, J. Y., Brundin, P., et al. (2005). Reduced hippocampal neurogenesis in R6/2 transgenic Huntington's disease mice. Neurobiol. Dis. 20, 744-751. doi: 10.1016/j.nbd.2005.05.006

Godin, J. D., Colombo, K., Molina-Calavita, M., Keryer, G., Zala, D., Charrin, B. C., et al. (2010). Huntingtin is required for mitotic spindle orientation and mammalian neurogenesis. Neuron 67, 392-406. doi: 10.1016/j.neuron.2010. 06.027 
Jacobsen, J. C., Gregory, G. C., Woda, J. M., Thompson, M. N., Coser, K. R., Murthy, V., et al. (2011). HD CAG-correlated gene expression changes support a simple dominant gain of function. Hum. Mol. Genet. 20, 2846-2860. doi: $10.1093 / \mathrm{hmg} / \mathrm{ddr} 195$

Kegel, K. B., Kim, M., Sapp, E., McIntyre, C., Castano, J. G., Aronin, N., et al. (2000). Huntingtin expression stimulates endosomal-lysosomal activity, endosome tubulation, and autophagy. J. Neurosci. 20, 7268-7278.

Keryer, G., Pineda, J. R., Liot, G., Kim, J., Dietrich, P., Benstaali, C., et al. (2011). Ciliogenesis is regulated by a huntingtin-HAP1-PCM1 pathway and is altered in Huntington disease. J. Clin. Invest. 121, 4372-4382. doi: 10.1172/JCI57552

Leavitt, B. R., Guttman, J. A., Hodgson, J. G., Kimel, G. H., Singaraja, R., Vogl, A. W., et al. (2001). Wild-type huntingtin reduces the cellular toxicity of mutant huntingtin in vivo. Am. J. Hum. Genet. 68, 313-324. doi: 10.1086/318207

Leavitt, B. R., van Raamsdonk, J. M., Shehadeh, J., Fernandes, H., Murphy, Z., Graham, R. K., et al. (2006). Wild-type huntingtin protects neurons from excitotoxicity. J. Neurochem. 96, 1121-1129. doi: 10.1111/j.1471-4159.2005. 03605.x

Lee, S. H., Lumelsky, N., Studer, L., Auerbach, J. M., and McKay, R. D. (2000). Efficient generation of midbrain and hindbrain neurons from mouse embryonic stem cells. Nat. Biotechnol. 18, 675-679. doi: 10.1038/76536

Liu, W., Zhou, H., Liu, L., Zhao, C., Deng, Y., Chen, L., et al. (2015). Disruption of neurogenesis and cortical development in transgenic mice misexpressing Olig2, a gene in the Down syndrome critical region. Neurobiol. Dis. 77, 106-116. doi: $10.1016 /$ j.nbd.2015.02.021

Lorincz, M. T., and Zawistowski, V. A. (2009). Expanded CAG repeats in the murine Huntington's disease gene increases neuronal differentiation of embryonic and neural stem cells. Mol. Cell. Neurosci. 40, 1-13. doi: 10.1016/ j.men.2008.06.004

Love, M. I., Huber, W., and Anders, S. (2014). Moderated estimation of fold change and dispersion for RNA-seq data with DESeq2. Genome Biol. 15, 550. doi: 10.1186/s13059-014-0550-8

Marcora, E., Gowan, K., and Lee, J. E. (2003). Stimulation of NeuroD activity by huntingtin and huntingtin-associated proteins HAP1 and MLK2. Proc. Natl. Acad. Sci. U.S.A. 100, 9578-9583. doi: 10.1073/pnas.113338 2100

Matsumoto, S., Banine, F., Feistel, K., Foster, S., Xing, R., Struve, J., et al. (2016). $\mathrm{Brg} 1$ directly regulates Olig2 transcription and is required for oligodendrocyte progenitor cell specification. Dev. Biol. 413, 173-187. doi: 10.1016/j.ydbio.2016. 04.003

Metzler, M., Chen, N., Helgason, C. D., Graham, R. K., Nichol, K., McCutcheon, K., et al. (1999). Life without huntingtin: normal differentiation into functional neurons. J. Neurochem. 72, 1009-1018.

Molero, A. E., Arteaga-Bracho, E. E., Chen, C. H., Gulinello, M., Winchester, M. L., Pichamoorthy, N., et al. (2016). Selective expression of mutant huntingtin during development recapitulates characteristic features of Huntington's disease. Proc. Natl. Acad. Sci. U.S.A. 113, 5736-5741. doi: 10.1073/pnas. 1603871113

Molero, A. E., Gokhan, S., Gonzalez, S., Feig, J. L., Alexandre, L. C., and Mehler, M. F. (2009). Impairment of developmental stem cell-mediated striatal neurogenesis and pluripotency genes in a knock-in model of Huntington's disease. Proc. Natl. Acad. Sci. U.S.A. 106, 21900-21905. doi: 10.1073/pnas. 0912171106

Molina-Calavita, M., Barnat, M., Elias, S., Aparicio, E., Piel, M., and Humbert, S. (2014). Mutant huntingtin affects cortical progenitor cell division and development of the mouse neocortex. J. Neurosci. 34, 10034-10040. doi: 10. 1523/JNEUROSCI.0715-14.2014

Mootha, V. K., Lindgren, C. M., Eriksson, K. F., Subramanian, A., Sihag, S., Lehar, J., et al. (2003). PGC-1alpha-responsive genes involved in oxidative phosphorylation are coordinately downregulated in human diabetes. Nat. Genet. 34, 267-273. doi: 10.1038/ng1180

Nasir, J., Floresco, S. B., O’Kusky, J. R., Diewert, V. M., Richman, J. M., Zeisler, J., et al. (1995). Targeted disruption of the Huntington's disease gene results in embryonic lethality and behavioral and morphological changes in heterozygotes. Cell 81, 811-823.

Nguyen, G. D., Gokhan, S., Molero, A. E., and Mehler, M. F. (2013a). Selective roles of normal and mutant huntingtin in neural induction and early neurogenesis. PLOS ONE 8:e64368. doi: 10.1371/journal.pone. 0064368
Nguyen, G. D., Molero, A. E., Gokhan, S., and Mehler, M. F. (2013b). Functions of huntingtin in germ layer specification and organogenesis. PLoS ONE 8:e72698. doi: 10.1371/journal.pone.0072698

Okabe, S., Forsberg-Nilsson, K., Spiro, A. C., Segal, M., and McKay, R. D. (1996). Development of neuronal precursor cells and functional postmitotic neurons from embryonic stem cells in vitro. Mech. Dev. 59, 89-102.

Ooi, J., Hayden, M. R., and Pouladi, M. A. (2015). Inhibition of excessive monoamine oxidase $\mathrm{A} / \mathrm{B}$ activity protects against stress-induced neuronal death in Huntington disease. Mol. Neurobiol. 52, 1850-1861. doi: 10.1007/s12035014-8974-4

Pal, A., Severin, F., Lommer, B., Shevchenko, A., and Zerial, M. (2006). HuntingtinHAP40 complex is a novel Rab5 effector that regulates early endosome motility and is up-regulated in Huntington's disease. J. Cell Biol. 172, 605-618. doi: 10.1083/jcb.200509091

Ravikumar, B., Vacher, C., Berger, Z., Davies, J. E., Luo, S., Oroz, L. G., et al. (2004). Inhibition of mTOR induces autophagy and reduces toxicity of polyglutamine expansions in fly and mouse models of Huntington disease. Nat. Genet. 36, 585-595. doi: 10.1038/ng1362

Rigamonti, D., Bauer, J. H., De-Fraja, C., Conti, L., Sipione, S., Sciorati, C., et al. (2000). Wild-type huntingtin protects from apoptosis upstream of caspase-3. J. Neurosci. 20, 3705-3713.

Ritch, J. J., Valencia, A., Alexander, J., Sapp, E., Gatune, L., Sangrey, G. R., et al. (2012). Multiple phenotypes in Huntington disease mouse neural stem cells. Mol. Cell. Neurosci. 50, 70-81. doi: 10.1016/j.mcn.2012.03.011

Saudou, F., and Humbert, S. (2016). The biology of Huntingtin. Neuron 89, 910-926. doi: 10.1016/j.neuron.2016.02.003

Schroeder, I. S., Wiese, C., Truong, T. T., Rolletschek, A., and Wobus, A. M. (2009). Differentiation analysis of pluripotent mouse embryonic stem (ES) cells in vitro. Methods Mol. Biol. 530, 219-250. doi: 10.1007/978-1-59745-471-1_12

Schwab, L. C., Garas, S. N., Drouin-Ouellet, J., Mason, S. L., Stott, S. R., and Barker, R. A. (2015). Dopamine and Huntington's disease. Expert Rev. Neurother. 15, 445-458. doi: 10.1586/14737175.2015.1025383

Seong, I. S., Woda, J. M., Song, J. J., Lloret, A., Abeyrathne, P. D., Woo, C. J., et al. (2010). Huntingtin facilitates polycomb repressive complex 2. Hum. Mol. Genet. 19, 573-583. doi: 10.1093/hmg/ddp524

Spiliotopoulos, D., Goffredo, D., Conti, L., Di Febo, F., Biella, G., Toselli, M., et al. (2009). An optimized experimental strategy for efficient conversion of embryonic stem (ES)-derived mouse neural stem (NS) cells into a nearly homogeneous mature neuronal population. Neurobiol. Dis. 34, 320-331. doi: 10.1016/j.nbd.2009.02.007

Steffan, J. S., Kazantsev, A., Spasic-Boskovic, O., Greenwald, M., Zhu, Y. Z., Gohler, H., et al. (2000). The Huntington's disease protein interacts with $\mathrm{p} 53$ and CREB-binding protein and represses transcription. Proc. Natl. Acad. Sci. U.S.A. 97, 6763-6768. doi: 10.1073/pnas.10011 0097

Strehlow, A. N., Li, J. Z., and Myers, R. M. (2007). Wild-type huntingtin participates in protein trafficking between the Golgi and the extracellular space. Hum. Mol. Genet. 16, 391-409. doi: 10.1093/hmg/ddl467

Subramanian, A., Tamayo, P., Mootha, V. K., Mukherjee, S., Ebert, B. L., Gillette, M. A., et al. (2005). Gene set enrichment analysis: a knowledge-based approach for interpreting genome-wide expression profiles. Proc. Natl. Acad. Sci. U.S.A. 102, 15545-15550. doi: 10.1073/pnas.0506580102

Takano, H., and Gusella, J. F. (2002). The predominantly HEAT-like motif structure of huntingtin and its association and coincident nuclear entry with dorsal, an NF-kB/Rel/dorsal family transcription factor. BMC Neurosci. 3:15. doi: 10.1186/ 1471-2202-3-15

Tattersfield, A. S., Croon, R. J., Liu, Y. W., Kells, A. P., Faull, R. L., and Connor, B. (2004). Neurogenesis in the striatum of the quinolinic acid lesion model of Huntington's disease. Neuroscience 127, 319-332. doi: 10.1016/j.neuroscience. 2004.04.061

Twelvetrees, A. E., Yuen, E. Y., Arancibia-Carcamo, I. L., MacAskill, A. F., Rostaing, P., Lumb, M. J., et al. (2010). Delivery of GABAARs to synapses is mediated by HAP1-KIF5 and disrupted by mutant huntingtin. Neuron 65 , 53-65. doi: 10.1016/j.neuron.2009.12.007

Vinther-Jensen, T., Nielsen, T. T., Budtz-Jorgensen, E., Larsen, I. U., Hansen, M. M., Hasholt, L., et al. (2016). Psychiatric and cognitive symptoms in Huntington's disease are modified by polymorphisms in catecholamine regulating enzyme genes. Clin. Genet. 89, 320-327. doi: 10.1111/cge.12628 
von Schimmelmann, M., Feinberg, P. A., Sullivan, J. M., Ku, S. M., Badimon, A., Duff, M. K., et al. (2016). Polycomb repressive complex 2 (PRC2) silences genes responsible for neurodegeneration. Nat. Neurosci. 19, 1321-1330. doi: 10.1038/nn.4360

Wang, Z. Q., Chen, K., Ying, Q. L., Li, P., and Shih, J. C. (2011). Monoamine oxidase A regulates neural differentiation of murine embryonic stem cells. J. Neural Transm. 118, 997-1001. doi: 10.1007/s00702-011-0655-0

White, J. K., Auerbach, W., Duyao, M. P., Vonsattel, J. P., Gusella, J. F., Joyner, A. L., et al. (1997). Huntingtin is required for neurogenesis and is not impaired by the Huntington's disease CAG expansion. Nat. Genet. 17, 404-410. doi: 10.1038/ng1297-404

Ying, Q. L., Wray, J., Nichols, J., Batlle-Morera, L., Doble, B., Woodgett, J., et al. (2008). The ground state of embryonic stem cell self-renewal. Nature 453, 519-523. doi: 10.1038/nature06968

Zala, D., Hinckelmann, M. V., and Saudou, F. (2013). Huntingtin's function in axonal transport is conserved in Drosophila melanogaster. PLoS ONE 8:e60162. doi: 10.1371/journal.pone.0060162

Zeitlin, S., Liu, J. P., Chapman, D. L., Papaioannou, V. E., and Efstratiadis, A. (1995). Increased apoptosis and early embryonic lethality in mice nullizygous for the Huntington's disease gene homologue. Nat. Genet. 11, 155-163. doi: $10.1038 / \mathrm{ng} 1095-155$
Zheng, S., Ghitani, N., Blackburn, J. S., Liu, J. P., and Zeitlin, S. O. (2012) A series of $\mathrm{N}$-terminal epitope tagged Hdh knock-in alleles expressing normal and mutant huntingtin: their application to understanding the effect of increasing the length of normal Huntingtin's polyglutamine stretch on CAG140 mouse model pathogenesis. Mol. Brain 5:28. doi: 10.1186/17566606-5-28

Zuccato, C., Tartari, M., Crotti, A., Goffredo, D., Valenza, M., Conti, L., et al. (2003). Huntingtin interacts with REST/NRSF to modulate the transcription of NRSE-controlled neuronal genes. Nat. Genet. 35, 76-83. doi: 10.1038/ ng1219

Conflict of Interest Statement: The authors declare that the research was conducted in the absence of any commercial or financial relationships that could be construed as a potential conflict of interest.

Copyright (C) 2017 Yu and Tanese. This is an open-access article distributed under the terms of the Creative Commons Attribution License (CC BY). The use, distribution or reproduction in other forums is permitted, provided the original author(s) or licensor are credited and that the original publication in this journal is cited, in accordance with accepted academic practice. No use, distribution or reproduction is permitted which does not comply with these terms. 